\title{
Ionic adsorption on the brucite (0001) surface: A periodic electrostatic embedded cluster method study
}

\author{
Eszter Makkos, ${ }^{1}$ Andrew Kerridge, ${ }^{1,2^{*}}$ Jonathan Austin, ${ }^{3}$ Nikolas Kaltsoyannis ${ }^{1,4^{*}}$ \\ ${ }^{I}$ Department of Chemistry, University College London, 20 Gordon Street, London WC1H OAJ, UK \\ ${ }^{2}$ Department of Chemistry, Lancaster University, Bailrigg, Lancaster LA1 4YP, UK \\ ${ }^{3}$ National Nuclear Laboratory, Chadwick House, Birchwood Park, Warrington, WA3 6AE, UK \\ ${ }^{4}$ School of Chemistry, The University of Manchester, Manchester, M13 9PL, UK
}

Study of ion/surface interactions on brucite reveals that the periodic electrostatic embedded cluster method is a viable alternative to periodic DFT for describing the adsorption of ionic species on a layered, not purely ionic solid. 


\section{Abstract}

Density functional theory at the GGA level is employed within the periodic electrostatic embedded cluster method (PEECM) to model the brucite (0001) surface. Three representative studies are then used to demonstrate the reliability of the PEECM for the description of the interactions of various ionic species with the layered $\mathrm{Mg}(\mathrm{OH})_{2}$ structure, and its performance is compared with periodic DFT, an approach known to be challenging for the adsorption of charged species. The adsorption energies of a series of $\mathrm{s}$ block cations, including $\mathrm{Sr}^{2+}$ and $\mathrm{Cs}^{+}$which are known to coexist with brucite in nuclear waste storage ponds, are well described by the embedded cluster model provided basis sets of triple-zeta quality are employed for the adsorbates. The substitution energies of $\mathrm{Ca}^{2+}$ and $\mathrm{Sr}^{2+}$ into brucite obtained with the PEECM are very similar to periodic DFT results, and comparison of the approaches indicates that two brucite layers in the quantum mechanical part of the PEECM are sufficient to describe the substitution. Finally, detailed comparison of the periodic and PEECM DFT approaches to the energetic and geometric properties of differently coordinated $\operatorname{Sr}\left[(\mathrm{OH})_{2}\left(\mathrm{H}_{2} \mathrm{O}\right)_{4}\right]$ complexes on brucite shows excellent agreement in adsorption energies, $\mathrm{Sr}-\mathrm{O}$ distances and bond critical point electron densities (obtained via the Quantum Theory of Atoms-in-Molecules), demonstrating that the PEECM can be a useful alternative to periodic DFT in these situations. 


\section{Introduction:}

Modelling ionic sorption mechanisms on surfaces is key to understanding a wide range of physical phenomena in catalytic chemistry ${ }^{1-5}$, biochemistry ${ }^{6,7}$, energy storage ${ }^{8,9}$ and environmental chemistry, where modelling has been used to study the migration of ion contaminants in soils and sediments, ${ }^{10-16}$ and the treatment of polluted water with adsorbent materials ${ }^{17-19}$. Computational studies can provide insight into ion/surface interactions at the molecular level by predicting preferred reaction sites, ${ }^{2,4,5,14,17}$ calculating the most stable structures during the interactions ${ }^{1,9,14,19}$ and allowing comparison of the interaction energies of competing species ${ }^{15,18,20}$.

However, choosing a suitable surface representation for the investigation of a particular adsorption mechanism is not always straightforward, and the choice can heavily influence the outcome of the results. By far the most common approach to model surfaces is periodic density functional theory $(\mathrm{DFT})^{21}$, which operates with conventional unit cells and employs periodic boundary conditions. However, modelling charged systems using periodic boundary conditions is extremely difficult ${ }^{9,22,23}$ and is often avoided by including counter ions in the simulation box. ${ }^{9,20}$ Furthermore, large super cells are often required to study isolated interaction sites, ${ }^{24-26}$ which significantly increases the computational cost.

One alternative to modelling a surface with periodic DFT is to use isolated molecular clusters to represent the adsorption site of the surface. This approach has been used mainly for $2 \mathrm{D}$ materials, such as graphene, ${ }^{18}$ where the far-field effects of the substrate on the adsorption reaction can be neglected, i.e. the interaction is very localised.

For adsorption on ionic crystals, embedded cluster methods are commonly used as an alternative to periodic DFT. ${ }^{24,27,28}$ These approaches have the advantage of being able to study isolated adsorption sites and can deal with charged systems with levels of theory beyond the generalised gradient approximation (GGA) methods typical of periodic DFT calculations. This last feature is especially useful for systems such as metal-oxides and oxygen defects of metal oxides, where hybrid functionals are necessary for the accurate description of the electronic structure. ${ }^{22,27,29,30}$ One such technique is the periodic electrostatic embedded cluster method (PEECM $)^{27,31}$ which features a quantum mechanically treated region (the QM cluster) embedded in an infinite periodic array of point charges (PCs). This 
approach provides an accurate description of the long range electrostatic interactions between the ionic crystal and the adsorption site by calculating the corresponding electrostatic potential via the periodic fast multipole method. ${ }^{32}$ A region intermediate between the QM cluster and the PCs is often necessary to prevent artificial over-polarisation of the former due to the neighbouring positive charges in the latter. ${ }^{31}$ The most common type of intermediate region represents the positive ions with softening effective core potentials and the negative ions with formal charges. ${ }^{24,27,29}$

The first generation of British civil nuclear power reactors used a Mg-Al alloy, called Magnox, as a fuel cladding. ${ }^{33}$ Much of this cladding (along with spent uranium oxide fuel) is currently stored in legacy ponds and silos, most notably in Sellafield, and has corroded to form heterogeneous sludges consisting mainly of brucite $\left(\mathrm{Mg}(\mathrm{OH})_{2}\right)$, along with other Mg-based minerals and uranium-oxides. ${ }^{34}$ The aqueous phase in the ponds contains a range of soluble radioisotopes, from which the biggest contributors to radioactivity are ${ }^{137} \mathrm{Cs}$ and ${ }^{90} \mathrm{Sr}^{35}$ Since there is only limited access to real samples and monitoring the conditions in-situ is difficult (due to the radiation hazards), computational modelling can play an important role in understanding the behaviour of the radioactive ions in the ponds and the environment, thus informing improvements in the waste treatment processes. There are several examples in the literature in which simulations have helped to improve our knowledge of radionuclide-related transport mechanisms in minerals ${ }^{36}$ by determining the strength and type of their interaction with transport media, such as molecular dynamics studies of the interaction of solvated uranyl ions with common soil components around nuclear waste depositaries, ${ }^{11,13,14,37,38}$ and computational investigations of ionic transport mechanisms in the filtration media used during the decommissioning process such as sand and zeolite type ion exchangers ${ }^{39,40}$.

Brucite contains layers of $\mathrm{Mg}(\mathrm{OH})_{2}$, where the hydroxyl groups are orthogonal to the hexagonal basal plane (space group $\mathrm{D}_{3 \mathrm{~d}}^{3}, \mathrm{P} 3 \mathrm{~m} 1$ ). The bulk structure of this material is well understood from previous experimental ${ }^{41,42}$ and computational studies. ${ }^{43-50}$ The interlayer distance is rather large due to the weak interlayer forces. Although some experimental results suggest a degree of hydrogen-bonding between the layers, ${ }^{51,52}$ the majority of previous studies predict only weak dispersion type forces, ${ }^{45,49,53}$ indicating that it is easy to cleave the structure. Theoretical studies agree that employing GGA or hybrid functionals for the crystal structure optimisation gives bulk geometrical parameters in good agreement with experiment ${ }^{45-47,49}$ but slightly underestimates the interaction energies between the 
$\mathrm{Mg}(\mathrm{OH})_{2}$ layers. ${ }^{46,47}$ Applying dispersion corrections with a hybrid functional gives a slightly better estimation for the strength of the interlayer attraction ${ }^{48}$ but predicts the interlayer distance to be shorter than the experimental value.

Based on the Wulff construction method, ${ }^{54}$ transmission electron microscopy and X-ray diffraction studies ${ }^{55}$ it is known that the brucite crystal forms in a hexagonal prismatic structure with (0001) and (1100) surfaces. The most stable and abundant face is the (0001) in which the hydroxide ions surround the magnesium ion in an octahedral coordination, resulting in a hexagonal ordered $\mathrm{Mg}^{2+}$ with the $\mathrm{OH}$ groups facing outwards.

We have previously identified computationally the most stable hydrate ${ }^{56}$ and hydroxide ${ }^{57,58}$ complexes of $\mathrm{Sr}^{2+}$ in aqueous solution and here move on to develop an efficient model for studying the adsorption of $\mathrm{Sr}^{2+}$ complexes on the hydrated (0001) brucite surface, using the PEECM, which has previously been employed to study ionic materials. ${ }^{24,27}$ Electronic structure calculations ${ }^{44}$ as well as Mulliken bond population analysis ${ }^{46}$ predict largely ionic character for the $\mathrm{Mg}$-O bond but more covalent character for the $\mathrm{O}-\mathrm{H}$ bond. This feature of the material allows us to employ embedded methods as for an ordinary metal oxide, as we define the QM cluster without cutting covalent bonds at the boundaries. Although there are a small number of examples for similar embedded calculations, ${ }^{59,60}$ to the best of our knowledge, this is the first time a surface of a not purely ionic material has been modelled with the PEECM.

Our paper is structured as follows. Sections 2.1 and 2.2 provide a detailed description of our computational surface models using the PEECM, and also our periodic DFT studies which we report for comparative purposes. Section 3.1 then presents a study of single ion adsorption using the developed embedded surface model in which we compare the adsorption energies of different s block ions and test the effect of using different basis sets on the relative adsorption energies. In sections 3.2 and 3.3 we show through two model cases that the embedded cluster model gives similar results for neutral systems as does periodic DFT and, by studying the effect of cell size with periodic DFT, we derive conclusions about the required size of the QM cluster. 


\section{Computational details:}

\subsection{PEECM model}

All calculations were performed with version 6.6 of the TURBOMOLE program $^{61}$ using resolution-of-the-identity density functional theory ${ }^{62}$. Results were visualised with the MOLDRAW chemical graphical software. ${ }^{63}$ The TPSS exchange-correlation functional, which employs the metageneralised gradient approximation (meta-GGA), ${ }^{64}$ was used as it has been shown to describe $\mathrm{Sr}^{2+}$ complexes well in the past ${ }^{56}$ and previous theoretical studies on brucite have shown that GGA functionals efficiently describe bulk properties. ${ }^{45-47}$ The brucite surface was considered as a slab containing 1 or 2 layers of $\mathrm{Mg}(\mathrm{OH})_{2}$ and modelled using the PEECM. In this approach, a finite sized cluster of brucite was treated quantum chemically and embedded in a 2D infinite array of point charges (PCs) (aperiodic in the $\mathrm{z}$ direction). The cluster was formed from a stoichiometric 6 by $6 \mathrm{Mg}$ atom unit cell $\left(\mathrm{Mg}_{36}(\mathrm{OH})_{72}\right)$ per layer of brucite, for which we use the following notation from now on: " $\boldsymbol{n} \boldsymbol{x} \boldsymbol{n} \_\boldsymbol{m}$ ", where $\boldsymbol{n}$ is the number of $\mathrm{Mg}$ atoms in the $\mathrm{x}$ and $\mathrm{y}$ direction and $\boldsymbol{m}$ is the number of brucite layers explicitly included in the cluster. The following surface representations were considered: a single layer $\left(\boldsymbol{6} \boldsymbol{x} \boldsymbol{6} \_\mathbf{1}\right)$ in which a $\mathrm{Mg}_{36}(\mathrm{OH})_{72}$ sized cluster was embedded, a double layer containing only point charges in the second layer $\left(6 x 6 \_1+P C\right)$ and a double layer in which the second layer has the same sized explicit cluster of brucite as the first $\left(\boldsymbol{6} \boldsymbol{x} \boldsymbol{6} \_2,2 \mathrm{xMg}_{36}(\mathrm{OH})_{72}\right)$. Due to the large size of the QM cluster, the def2-SVP basis sets of polarised double- $\zeta$ quality ${ }^{65,66}$ were used for all QM atoms. Partial geometry optimisations, in which the boundary atoms of the cluster were held fixed and the inner atoms allowed to fully relax (see Figure 1 ) ${ }^{67}$ were carried out in the gas phase, with the m4 integration grid and the default convergence criteria: SCF energy: $10^{-6}$ a.u., structural energy: $10^{-6}$ a.u. and energy gradient: $10^{-3}$ a.u. 


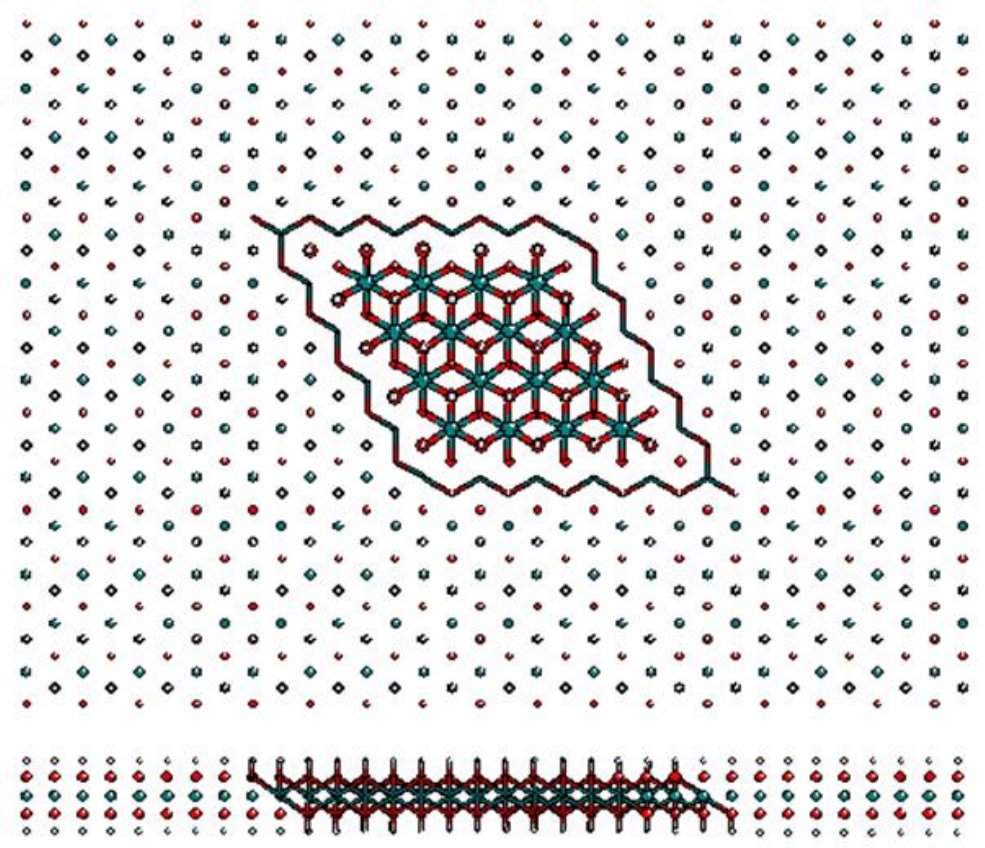

Figure 1: Illustration of the top and side view of the single layer PEECM model (6x6_1). The point charges are represented as balls around the QM cluster, the fixed boundary atoms as wires and the inner part of the cluster as balls and sticks. Bonds between the inside cluster and the boundary atoms are not shown for clarity. ( $\mathrm{Mg}=$ green, $\mathrm{O}=$ red, $\mathrm{H}=$ grey)

Experimental cell parameters, obtained via neutron diffraction measurements by Catti et al., ${ }^{41}$ were used to define both the initial geometry for the QM cluster and the positions of the PCs in the infinite two dimensional array: the $a$ and $b$ lattice parameters of the hexagonal unit cell were $3.15 \AA$, and the interlayer distance $c$ was $4.77 \AA$.

To best of our knowledge, the PEECM approach has been previously used only for purely ionic materials often with conventional unit cell structures such as $\mathrm{TiO}_{2}{ }^{24}$ or $\mathrm{CeO}_{2}{ }^{27}$. For these metal oxides effective core potentials (ECPs) were used on the neighbouring cations around the QM cluster to soften the effect of polarisation from the positive charges, as discussed in the Introduction, while formal charges were used on the corresponding anions. By contrast to these examples, brucite has a layered structure, in which the covalently bonded $\mathrm{OH}$ group carries a -1 charge. In this case, the use of an ECP region is complicated, in that we do not wish to apportion formal charges to the $\mathrm{O}$ and $\mathrm{H}$ atoms in the covalently bound $\mathrm{OH}$ units. Therefore, to avoid the artificial polarisation effect of neighbouring PCs on the QM cluster, we decided to employ natural charges in the PC region, ${ }^{68}$ derived iteratively from natural population analysis (NPA) ${ }^{69}$ Formal charges were used as an initial guess for the embedding array in a single point calculation, from which a new set of NPA charges 
inside the QM cluster was determined. The values obtained from the centre of the QM cluster were used as charges in the PC region for the following calculation and this step was repeated until no further variation occurred. The following natural charges were obtained through this process: $\mathrm{Mg}=$ $+1.78, \mathrm{O}=-1.33$ and $\mathrm{H}=+0.44$. Applying these charges in the partial optimisation resulted in good geometrical agreement with experimental data (see supplementary material (SM) section 1.1), especially regarding the key features of the surface, such as the perpendicular position of the $\mathrm{OH}$ groups to the (0001) plane and the planarity of the Mg sites.

For every s block ion investigated in section $3.1\left(\mathrm{Na}^{+}, \mathrm{Rb}^{+}, \mathrm{Cs}^{+}\right.$and $\left.\mathrm{Mg}^{2+}, \mathrm{Sr}^{2+}, \mathrm{Ba}^{2+}\right)$, the def2SVP basis set ${ }^{65,66,70}$ was used during the geometry optimisation along with the associated effective core potentials $^{71}$ for $\mathrm{Rb}, \mathrm{Cs}, \mathrm{Sr}$ and $\mathrm{Ba}$. The electron density distribution calculations reported in section 3.1 were performed by generating wavefunction (.wfn) files from the output of the optimisation in TURBOMOLE using the molden2aim program $^{72}$ which served as an input for the Multiwfn code ${ }^{73}$. The electron density images were plotted with the $\mathrm{VMD}^{74}$ visualisation code, using an isosurface value of \pm 0.0025 a.u.

The Quantum Theory of Atoms-in-Molecules (QTAIM) calculations described in section 3.3 were performed with the professional version 13.11.04 of AIMAll ${ }^{75}$ using the default parameters of the program. The required .wfn files were generated as described above.

\subsection{Periodic DFT model}

We chose the CRYSTAL14 code ${ }^{76,77}$ to model the brucite (0001) surface with periodic DFT, since this program allows us to use atom-centred basis sets, as used in TURBOMOLE. The TPSS meta-GGA exchange correlation functional, which was used for the development of the PEECM model, is not available in this code. Since TPSS was developed by Perdew and co-workers based on the same philosophy as PBE exchange-correlation functional ${ }^{78}$, we decided to use the latter in CRYSTAL14. PBE is one of the most commonly employed GGA functionals in solid state chemistry, and the GGA level of theory gave good agreement with the experimental parameters of brucite in previous studies. ${ }^{45-47,49}$ Following on from the work of Ungliengo et al. ${ }^{48}$, we compared the geometrical parameters obtained with PBE to the Grimme type dispersion corrected PBE-D 
functional ${ }^{79,80}$. Since PBE-D resulted in an interlayer distance $0.15 \AA$ less than the experimental values, we decided to continue with PBE [see SM, Table (iii)].

Polarised triple- $\zeta$ basis sets, derived specifically for solid state calculations by Peintinger et al ${ }^{81}$ were used for the surface atoms (Mg_pob_TZVP_2012, O_pob_TZVP_2012, H_pob_TZVP_2012) along with the $\mathrm{Ca}$ atom in the substitution study presented in section 3.2 (Ca_pob_TZVP_2102). In the case of Sr, the Sr_HAYWSC-311(d11f)G basis set ${ }^{82}$ was used for geometry optimisations, whilst single point energies were calculated using doubly polarised triple- $\zeta$ basis sets for the valence electrons with the ECP28MWB multi-electron fit quasi-pseudopotential on the electrons of the core $1 \mathrm{~s}-3 \mathrm{~d}$ orbitals. ${ }^{71}$

Creating starting geometries for the brucite surface in CRYSTAL14 involves several intermediate steps. ${ }^{83}$ The results of these calculations are given in the SM section 1.2. A full optimisation was performed on the primitive cell of bulk brucite, using a shrinking factor of 8 along with the energy criteria of $10^{-7}$ a.u. both for the SCF energy convergence and for the geometry optimisation. These parameters gave good agreement of geometrical properties with the experimental values as well as previous computational studies $(a, b=3.177 \AA$ and $c=4.751 \AA)$. We fixed the optimised lattice parameters of the bulk system to create a primitive cell for the (0001) surface and calculated the surface energy along with the Mulliken charges and populations for slabs incorporating different numbers of layers. (One layer of $\mathrm{Mg}(\mathrm{OH})_{2}$ contains 5 atomic layers as shown in Figure 2). Since, as was discussed in the Introduction, there are only weak dispersion forces between the layers in brucite, including a $2^{\text {nd }}$ layer in the unit cell has only a small effect on the surface energy $\left(\sim 10^{-6} \mathrm{~J} / \mathrm{m}^{2}\right)$, although three layers were required to recover the exact Mulliken charges of the bulk in the middle of the slab.

For the model studies in section 3.2 and 3.3, we created a series of $\mathrm{Mg}(\mathrm{OH})_{2}$ slabs with different supercell sizes $(3 \times 3,5 x 5,7 x 7$ and $9 x 9)$ and with 1, 2 and 3 layers of brucite (Figure 2) and optimised the internal coordinates for each using a shrinking factor of 4 along with the convergence criteria: SCF energy: $10^{-7}$ a.u. and structural energy: $10^{-7}$ a.u.. We used the OD 'MOLECULE' option of CRYSTAL14 for the single point energies of the isolated ions in section 3.2 and for the solvated $\mathrm{Sr}(\mathrm{OH})_{2}$ complex in section 3.3. ${ }^{84}$ 
For the model studies presented in sections 3.2 and 3.3, to make comparison between the two different methods possible, we used the PBE functional with the same computational parameters for the PEECM calculations as was detailed for periodic DFT. Although for the embedded cluster structures def2-SVP basis sets were used for the geometry optimisation, single point energies were obtained after geometry optimisation with the above defined CRYSTAL14 basis functions.

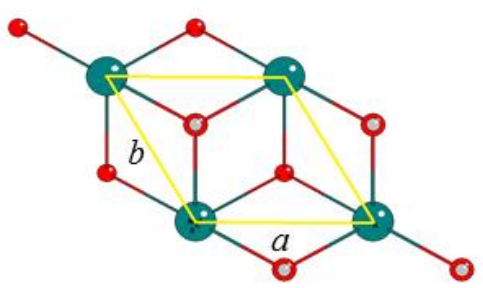

a

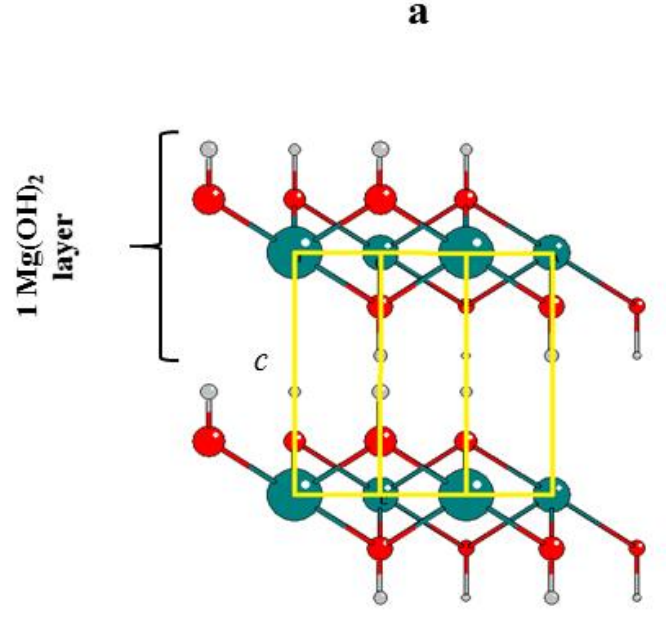

b

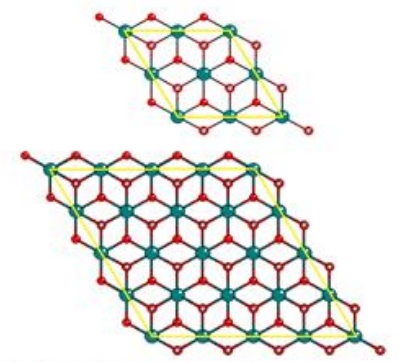

$3 \times 3$

$5 \times 5$

$7 \times 7$

$9 \times 9$

Figure 2: a) Top view of the hexagonal unit cell in the brucite crystal structure $(a, b$ are lattice parameters) b) Side view of the hexagonal unit cell, $c$ is the interlayer distance. 1 $\operatorname{Mg}(\mathrm{OH})_{2}$ layer contains 5 atomic layers. c) Illustration of the supercells employed $(\mathrm{Mg}=$ green, $\mathrm{O}=$ red, $\mathrm{H}=$ grey) 


\section{Results and discussion}

In this section, we present the results of three model studies in which we test the reliability of the embedded cluster model developed for the brucite (0001) surface. First, we examine the adsorption of charged systems, by investigating the interaction of a series of s block ions with brucite. Then, we move on to compare the embedded model calculations with a more widely established method (periodic DFT); we perform a substitution study for single ions into brucite and a second in which we look at the adsorption of differently coordinated $\left[\mathrm{Sr}(\mathrm{OH})_{2}\left(\mathrm{H}_{2} \mathrm{O}\right)_{4}\right]$ complexes on the surface, comparing their relative stability. We also used the periodic DFT model to carry out cell size studies on the systems of interest and to (indirectly) verify the size of the quantum chemically treated cluster in the PEECM approach.

Note that the adsorption and substitution energies presented in sections 3.1 and 3.2 are calculated without considering the effects of solvation on the adsorbed or substituted ions. This has been done because the purpose of these calculations is to provide as direct and straightforward a comparison of periodic DFT and PEECM as possible, without the extra variability and complication that will inevitably arise from the treatment of solvation.

\subsection{Single ion adsorption of $\mathrm{Sr}^{2+}$ and other $\mathrm{s}$ block elements on brucite}

We calculated adsorption energies for a series of ions: $\mathrm{Na}^{+}, \mathrm{Rb}^{+}, \mathrm{Cs}^{+}$and $\mathrm{Mg}^{2+}, \mathrm{Sr}^{2+}, \mathrm{Ba}^{2+}$ from which $\mathrm{Na}^{+}, \mathrm{Cs}^{+}, \mathrm{Sr}^{2+}$ and $\mathrm{Mg}^{2+}$ are known to exist in the aqueous phase in Magnox storage ponds. ${ }^{35} \mathrm{As}$ described in the Introduction, we have a special interest in ${ }^{90} \mathrm{Sr}^{2+}$ and ${ }^{137} \mathrm{Cs}^{+}$, as their adsorption behaviour is especially important in the waste treatment process. We included $\mathrm{Rb}^{+}$and $\mathrm{Ba}^{2+}$ to make the series of the singly and doubly charged ions more complete, and to allow us to test if the adsorption energies follow the trend expected based on the ionic radii and charges, i.e. the dications should have a stronger interaction with the surface, and the interaction energy should decrease with decreasing ionic charge density.

The following equation was used to calculate the adsorption energies presented in Table I:

$$
E_{\text {ads }}=E_{\text {complex }}-\left(E_{\text {brucite }}+E_{M^{2+}}\right) \quad \text { Eq. } 1
$$


$E_{\text {complex }}$ is the SCF energy of the adsorbed ion with the surface, while $E_{\text {brucite }}$ is the energy of the brucite surface model $\left(\boldsymbol{6} \boldsymbol{x} \boldsymbol{6} \_\mathbf{1}, \boldsymbol{6} \boldsymbol{x} \boldsymbol{6} \_\mathbf{1}+\boldsymbol{P C}\right.$, or $\left.6 x \boldsymbol{6} \_2\right)$ and $E_{M^{2+}}$ is the energy of the adsorbed ion. The counterpoise (CP) correction ${ }^{85}$ was included to compensate for the artificial energy contribution to the adsorption energy due to the difference in the basis set sizes applied for the components of Eq. 1 (basis set superposition error, BSSE). CP corrected results are shown in brackets in Table I. 
TABLE I: Adsorption energies $\left(E_{\text {ads }}\right)$ of a series of $s$ block ions and relative adsorption energies of different surface representations for a given ion, calculated by comparing the results to the adsorption energy of the $6 x 6 \_1$ structures $\left(\Delta E_{\text {ads }}\right)$. Counterpoise corrected energy values are presented in brackets (BSSE). (The adsorption energies with ion-SVP and ion-TZVP mixed basis sets were not calculated for $6 x 6 \_1+P C$.)

\begin{tabular}{|c|c|c|c|c|c|c|c|c|c|c|}
\hline \multicolumn{2}{|c|}{ Studied system } & \multicolumn{5}{|c|}{$E_{\text {ads }}(\mathbf{k J} / \mathbf{m o l})$} & \multicolumn{4}{|c|}{$\Delta E_{\text {ads }}(\mathrm{kJ} / \mathrm{mol})$} \\
\hline ion & layer & $\begin{array}{ll}\text { def2- } & \text { (BSSE) } \\
\text { SVP } & \text { (BS } \\
\end{array}$ & $\begin{array}{ll}\text { def2- } & \\
\text { TZVP }\end{array}$ & \begin{tabular}{|l|} 
ion - \\
TZVP
\end{tabular} & $\begin{array}{l}\text { ion - } \\
\text { SVP } \\
\end{array}$ & (BSSE) & def2-SVP & def2-TZVP & ion-TZVP & ion - SVP \\
\hline \multirow{3}{*}{$\mathbf{N a}^{+}$} & $6 x 6 \_1$ & $-131.0(-118.2)$ & $-249.7(-244.7)$ & $-290.6(-277.2)$ & -96.2( & $(-93.7)$ & 0.0 & 0.0 & 0.0 & 0.0 \\
\hline & $+P C$ & $-131.9(-119.2)$ & $-248.8 \quad(-244.6)$ & - & - & - & $-0.9(-1.1)$ & $0.9(0.0)$ & - & - \\
\hline & $6 x 6 \_2$ & $-123.6(-107.8)$ & $-212.1 \quad(-206.7)$ & $-284.0(-267.4)$ & -58.8( & $(-55.9)$ & $7.4(13.3)$ & $37.6(38.0)$ & $6.7(9.8)$ & $37.3(37.8)$ \\
\hline \multirow{3}{*}{$\mathbf{R} \mathbf{b}^{+}$} & $6 x 6 \_1$ & $-144.7(-136.4)$ & $-112.7(-108.7)$ & $-149.3(-138.5)$ & -110.1 & $(-106.8)$ & 0.0 & 0.0 & 0.0 & 0.0 \\
\hline & $+P C$ & $-144.7(-136.6)$ & $-110.5(-106.7)$ & - & - & - & $0.1 \quad(0.2)$ & $2.2(2.0)$ & - & - \\
\hline & $6 x 6 \_2$ & $-135.1(-124.6)$ & $-76.1 \quad(-71.5)$ & $141.5(-127.2)$ & -73.0 & $(-69.7)$ & $9.6(11.8)$ & $36.6(37.2)$ & $7.8(11.4)$ & $37.1(37.1)$ \\
\hline \multirow{3}{*}{$\mathrm{Cs}^{+}$} & $6 x 6 \_1$ & $-118.0(-109.6)$ & $-94.5 \quad(-91.3)$ & $-127.9(-119.4)$ & -85.0 & $(-82.0)$ & 0.0 & 0.0 & 0.0 & 0.0 \\
\hline & $+P C$ & $-117.5(-109.3)$ & $-92.1 \quad(-89.2)$ & - & - & - & $0.5(0.3)$ & $2.4(2.2)$ & - & - \\
\hline & $6 x 6 \_2$ & $-108.9(-98.5)$ & $-57.9 \quad(-54.5)$ & $-119.1(-108.5)$ & -48.8 & $(-45.6)$ & $9.1(11.1)$ & $36.6(36.9)$ & $8.8(10.9)$ & $36.2(36.4)$ \\
\hline \multirow{3}{*}{$\mathrm{Mg}^{2+}$} & $6 x 6 \_1$ & $-1182.7(-1161.4)$ & $-1319.6(-1311.6)$ & $-1387.0(-1363.0)$ & -1123.7 & $(-1117.7)$ & 0.0 & 0.0 & 0.0 & 0.0 \\
\hline & $+P C$ & $-1184.2(-1168.0)$ & $-1315.6(-1308.3)$ & - & - & - & $-1.5(-6.6)$ & $4.0(3.3)$ & - & - \\
\hline & $6 x 6 \_2$ & $-1199.2(-1178.1)$ & $-1272.5(-1265.3)$ & $-1404.6(-1379.9)$ & -1077.6 & $(-1072.2)$ & $-16.5(-16.7)$ & $47.1(46.3)$ & $-17.6(-16.9)$ & $46.1(45.5)$ \\
\hline \multirow{3}{*}{$\mathrm{Sr}^{2+}$} & $6 x 6 \_1$ & $-890.9(-874.6)$ & $-835.4(-828.5)$ & $-901.7(-882.1)$ & -825.6 & $(-819.5)$ & 0.0 & 0.0 & 0.0 & 0.0 \\
\hline & $+P C$ & $-895.2(-880.0)$ & $-834.6 \quad(-828.1)$ & - & - & - & $-4.3(-5.4)$ & $0.8(0.4)$ & - & - \\
\hline & $6 x 6 \_2$ & $-898.5(-881.2)$ & $-780.5 \quad(-774.1)$ & $-908.8 \quad(-888.4)$ & -771.3 & $(-765.7)$ & $-7.6(-6.6)$ & $54.9(54.4)$ & $-7.2(-6.3)$ & $54.3(53.8)$ \\
\hline $\mathbf{B a}^{2+}$ & $6 x 6 \_1$ & $-717.9(-702.3)$ & $-730.1 \quad(-721.7)$ & $-793.4(-777.4)$ & -653.3 & $(-647.8)$ & 0.0 & 0.0 & 0.0 & 0.0 \\
\hline
\end{tabular}




\begin{tabular}{|c|c|c|c|c|c|c|c|c|}
\hline$+P C$ & $-722.6(-707.6)$ & $-729.4(-723.7)$ & - & - & $-4.7(-5.3)$ & $0.7(-2.0)$ & - & - \\
\hline 6 & $-723.5(-706.1)$ & $-674.1 \quad(-665.9)$ & $-798.8(-781.5)$ & $-598.6(-591.5)$ & $-5.5(-4.4)$ & $55.9(55.8)$ & $-5.4(-4.1)$ & $54.7(56.3)$ \\
\hline
\end{tabular}


The doubly charged ions indeed have a stronger interaction with the surface, the adsorption energy of $\mathrm{Mg}^{2+}, \mathrm{Sr}^{2+}$ and $\mathrm{Ba}^{2+}$ being almost an order of magnitude stronger $(\sim 700-1200 \mathrm{~kJ} / \mathrm{mol})$ than the adsorption energy of $\mathrm{Na}^{+}, \mathrm{Rb}^{+}$and $\mathrm{Cs}^{+}(\sim 100 \mathrm{~kJ} / \mathrm{mol})$. This difference is probably due to the greater polarisation effect of the dications, as is shown by the electron density difference plots of $\mathrm{Sr}^{2+}$ and $\mathrm{Cs}^{+}$in Figure 3. The blue regions represent electron accumulation while the red areas indicate electron depletion caused by ion adsorption. $\mathrm{Sr}^{2+}$ clearly polarises the oxygen atoms of the brucite cluster much more than $\mathrm{Cs}^{+}$does; most likely that is why the $\mathrm{Sr}^{2+}$ binds much more strongly to the surface. Besides showing the different behaviour of the ions, the electron density difference plots also reassure us that there is no artificial polarisation at the edges of the cluster, caused by false interaction between the charged systems and the point charge region. Furthermore, the image $\mathbf{b}$ and $\mathbf{d}$ in Figure 3 suggest only a small contribution from the $2^{\text {nd }}$ layer oxygen atoms to the interaction even in the case of $\mathrm{Sr}^{2+}$.
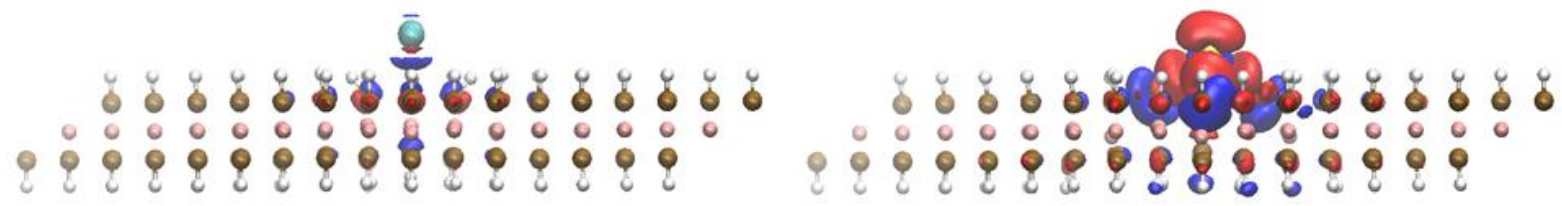

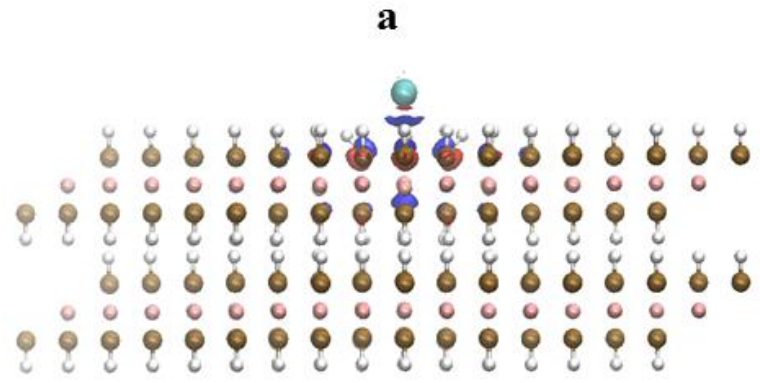

b

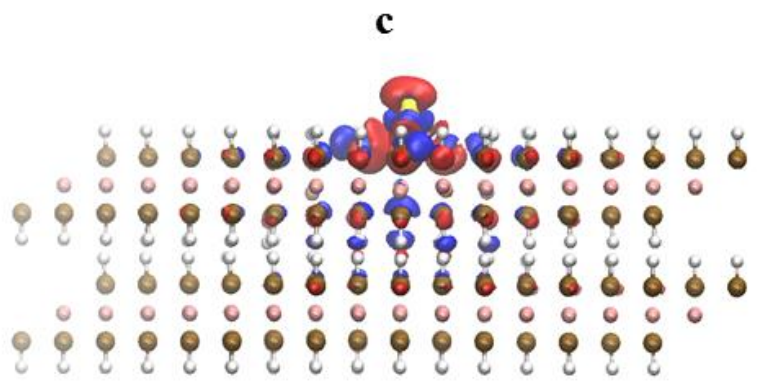

d

Figure 3: Electron density difference plots of adsorbed $\mathrm{Cs}^{+}(\mathrm{a}, \mathrm{b})$ and $\mathrm{Sr}^{2+}$ ion $(\mathrm{c}, \mathrm{d})$ on $6 x 6 \_1$ (a,c) and on 6x6_2 (b,d). The isosurface value was chosen to be 0.0025 a.u. throughout. The red regions are indicative of electron depletion, while the blue regions to electron accumulation. Point charges are not shown. $(\mathrm{Mg}=$ pink, $\mathrm{O}=$ ochre, $\mathrm{H}=$ white, $\mathrm{Sr}=$ yellow, Cs=turquoise $)^{74}$

Examination of the energy trends for the ions of the same charge reveals that, in the case of the monocations, there is a deviation from the expected order of the adsorption; a weaker interaction is predicted for $\mathrm{Na}^{+}$than $\mathrm{Rb}^{+}$. This discrepancy does not vary with the number of layers included in the 
cluster, however, it is eliminated by the use of a higher quality basis set: as is shown in Figure 4, using triple- $\zeta$ basis sets (def2-TZVP) gives the expected energetic order. ${ }^{86}$

As expected, correcting for the effect of BSSE on the adsorption energies (shown in brackets in Table I) generally decreases the strength of the interaction, and the magnitude of the counterpoise correction is smaller when higher quality basis sets are used; the energetic order between the ions is not altered.

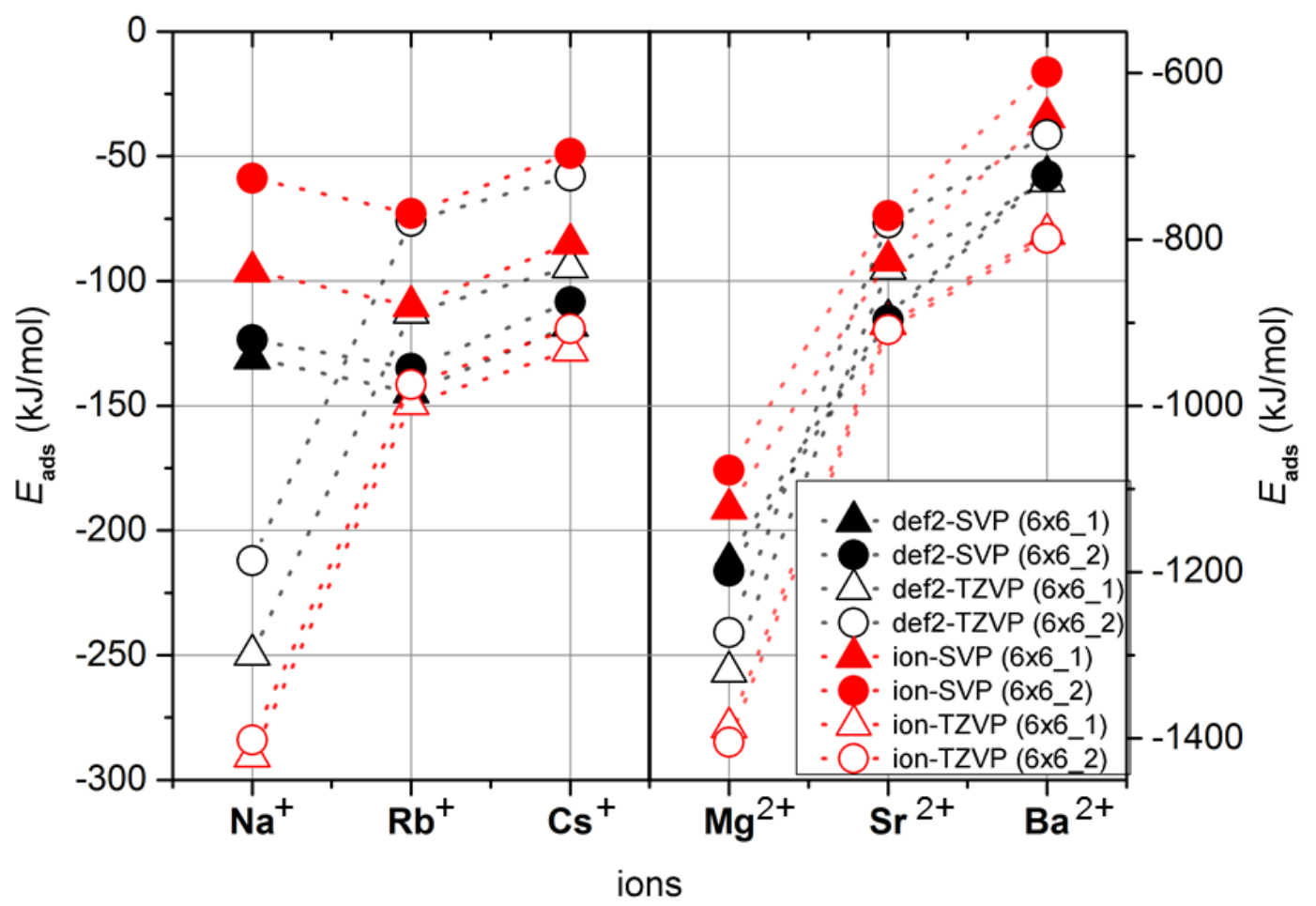

Figure 4: Adsorption energies for a series of ions adsorbed on the $6 x 6 \_1$ and $6 x 6 \_2$ model surfaces, using different quality basis sets (def2-SVP, def2-TZVP or mixed basis sets)

To understand the effect of the surface representation on the adsorption energies, we looked at the adsorption of the same ions on three different surface models, a single layer, $6 \boldsymbol{6} \boldsymbol{6} \_\_$, a surface containing a point charge layer underneath the QM cluster, $6 \boldsymbol{x} 6 \_1+P C$, and a double layer with the same sized QM clusters in both, 6x6_2. The relative adsorption energies were calculated by comparing the energies of the different systems to the original single layer results (see Table I). Including an extra PC layer $\left(\boldsymbol{6} \boldsymbol{x} \boldsymbol{6} \_\mathbf{1}+\boldsymbol{P C}\right)$ results in negligible difference in the adsorption energies. With def2-SVP basis sets, the $\Delta E_{\text {ads }}$ are c. $0.9 \mathrm{~kJ} / \mathrm{mol}$ for $\mathrm{Na}^{+}, \mathrm{Rb}^{+}$and $\mathrm{Cs}^{+}$, while they are slightly larger (1.5- $4.7 \mathrm{~kJ} / \mathrm{mol}$ ) for $\mathrm{Mg}^{2+}, \mathrm{Sr}^{2+}$ and $\mathrm{Ba}^{2+}$. To place these differences in context, they are no 
more than $\sim 0.7 \%$ of the original interaction energies in each case. These results suggest that the electrostatic contribution of the second layer to the ion/surface interaction is small.

Including the atoms of the second layer in the quantum chemically treated cluster $\left(6 x 6 \_2\right)$ increases the dication adsorption energies slightly (except for $\mathrm{Mg}^{2+}$ due to its different behaviour compared to $\mathrm{Sr}^{2+}$ and $\mathrm{Ba}^{2+},{ }^{87}$ see SM Figure (i)) but the opposite is true for the monocations, for which the energies decrease by 7.4-9.7 kJ/mol, 6-8 \% of the actual adsorption energies. These values are in line with our previous suggestion based on Figure 3, i.e. that there is only a small electron donation from the second layer oxygens in the case of $\mathrm{Sr}^{2+}$ and a negligible effect for $\mathrm{Cs}^{+}$. We conclude that the adsorption of singly charged ions slightly distorts the positions of the second layer atoms, but with minimal polarisation, therefore a quantum chemically treated second layer weakens the interactions overall.

A problem emerges when we use higher quality basis sets for the $\boldsymbol{6} \boldsymbol{x} \boldsymbol{6} \_\mathbf{2}$ systems. The relative adsorption energies with the def2-TZVP basis sets are $\sim 36 \mathrm{~kJ} / \mathrm{mol}$ for the monocations and $\sim 55$ $\mathrm{kJ} / \mathrm{mol}$ for the diactions. The significant shifts in energies, which are more than the $30 \%$ of the actual adsorption energies for the singly charged ions, are very likely the consequence of an artificial interaction. Larger basis sets might cause charge density increase closer to or overlapping the PC region leading to a falsely enhanced interaction. (The point charges were originally calculated with NPA in an iterative process using SVP quality basis sets for the QM cluster). To probe this further, we explored a range of mixed basis set calculations. Ion-TZVP in Table I and Figure 4 indicates systems with the def2-SVP basis set on the surface atoms but def2-TZVP on the adsorbed ion - and vice versa for Ion-SVP. Based on these results, we find that the deviation from the expected order in adsorption energies is clearly a function of basis set quality on the adsorbed ion, while the shift in the relative adsorption energies is related only to the basis sets of the surface atoms.

In summary, we conclude that our PEECM brucite model is capable of describing the energetics of ion/surface interactions, providing sufficiently high quality basis sets are applied on the ions. Considering the surface as a two layered slab only slightly affects the adsorption energies, which suggests only a small contribution from the second layer atoms in the interaction. 


\subsection{Substitution of $\mathrm{Ca}^{2+}$ and $\mathrm{Sr}^{2+}$ into brucite}

Our next study focussed on the energetics of substitution of heavier group II ions for $\mathrm{Mg}^{2+}$ in brucite, calculated with both the PEECM model and periodic DFT, using the same functional (PBE) and basis sets (section 2.2) with the two different codes. We optimised structures with one (6x6_1) and two $\left(\boldsymbol{6} \boldsymbol{x} \_\_2\right)$ layers included in the QM cluster for the PEECM model, excluding the $6 \boldsymbol{x} \boldsymbol{6} \_\mathbf{1 + P C}$ surface representation which is not easily comparable with periodic DFT. We substituted each ion into the same position in the upper layer to avoid the possible effect of different relative positions related to the cluster boundaries. We considered four different supercell sizes with 1, 2 and 3 layers of brucite within the periodic DFT model. The following equation was used to calculate the substitution energy:

$$
E_{\text {sub }}=\left(E_{\text {brucite-M }}+E_{M g^{2+}}\right)-\left(E_{\text {brucite-Mg }}+E_{M^{2+}}\right) \quad \text { Eq. } 2
$$

$E_{\text {brucite-M }}$ is the computed SCF energy of the optimised substituted structure, $E_{\text {brucite-Mg }}$ is the energy of the perfect brucite slab with the same surface representation as $E_{\text {brucite-M }}$, while $E_{M g^{2+}}$ and $E_{M^{2+}}$ are the single point energies of the isolated ions.

The substitution energies are summarised in Table II. Both models yield the expected order based on the size of the ionic radii $\left(72 \mathrm{pm}\left(\mathrm{Mg}^{2+}\right)<95 \mathrm{pm}\left(\mathrm{Ca}^{2+}\right)<118 \mathrm{pm}\left(\mathrm{Sr}^{2+}\right)\right)$, i.e. the substitution of $\mathrm{Ca}^{2+}$ is less unfavoured than that for $\mathrm{Sr}^{2+}$. If we compare the energies obtained with the largest $(\mathbf{9} \boldsymbol{x} \boldsymbol{9})$ cell size in the periodic DFT calculations to the results of the isolated PEECM model, the two methods give reasonably similar results. Although the difference between them is not constant for the two ions, it is always less than c. $6 \%$ of the substitution energies. Including a $2^{\text {nd }}$ layer of brucite in the surface model has only a slight effect on the substitution energy, which is interesting given that the substitution distorts the surface geometry much more than an adsorption reaction. The $2^{\text {nd }}$ layer results in only a 2-6 kJ/mol difference in energy for each ion, irrespective of the method used. 
TABLE II: Substitution energies $\left(E_{\text {sub }}\right)$ calculated with periodic DFT and with the PEECM, including 1 or 2 explicit layers of brucite in the model. The energy differences between the two models are represented in percentages $\left(E_{\text {diff }}\right)$ relative to the periodic DFT values

\begin{tabular}{|c|c|c|c|c|c|}
\hline \multicolumn{2}{|c|}{ Surface models } & \multicolumn{4}{|c|}{ Substitution energies } \\
\hline \multirow{2}{*}{ Method } & \multirow{2}{*}{ layer } & \multicolumn{2}{|c|}{$\mathrm{Ca}^{2+}$} & \multicolumn{2}{|c|}{$\mathrm{Sr}^{2+}$} \\
\hline & & $E_{\text {sub }}(\mathrm{kJ} / \mathrm{mol})$ & $E_{\text {diff }}(\%)$ & $E_{\text {sub }}(\mathrm{kJ} / \mathrm{mol})$ & $E_{\text {diff }}(\%)$ \\
\hline Periodic DFT & $9 \times 9 \_1$ & 446.8 & & 571.5 & \\
\hline PEECM & $6 \times 6 \_1$ & 456.1 & 2.1 & 598.2 & 4.7 \\
\hline Periodic DFT & $9 \times 9 \_2$ & 441.0 & & 567.2 & \\
\hline PEECM & $6 x 6 \_2$ & 453.4 & 2.8 & 601.9 & 6.1 \\
\hline
\end{tabular}

The substitution energies as a function of cell size for different number of layers are plotted in Figure 5 (and summarised in SM Table (x)). With the use of bigger cell sizes in the periodic DFT model the substitution energy converges, presumably towards the energy of a completely isolated interaction site. However, with cell sizes bigger than $3 \times 3$ the differences are small, 3-5 $\mathrm{kJ} / \mathrm{mol}$ for each case, i.e. the effect of the substituted ion on the crystal structure is so localised that the ions are close to being isolated even with a $5 \times 5$ supercell. Adding a $2^{\text {nd }}$ layer lowers the energy by $4-6 \mathrm{~kJ} / \mathrm{mol}$ and including a $3^{\text {rd }}$ layer has an even much smaller effect on the energies.

This study of $\mathrm{Ca}^{2+}$ and $\mathrm{Sr}^{2+}$ substitution within a periodic DFT model suggests that moving from two- to three-layer slabs has little effect on substitution energies. This provides indirect evidence that the $6 x \boldsymbol{6} \_2$ QM cluster in the PEECM model includes all the necessary interactions and there is no need to increase the cluster size or the number of brucite layers in the QM region. 

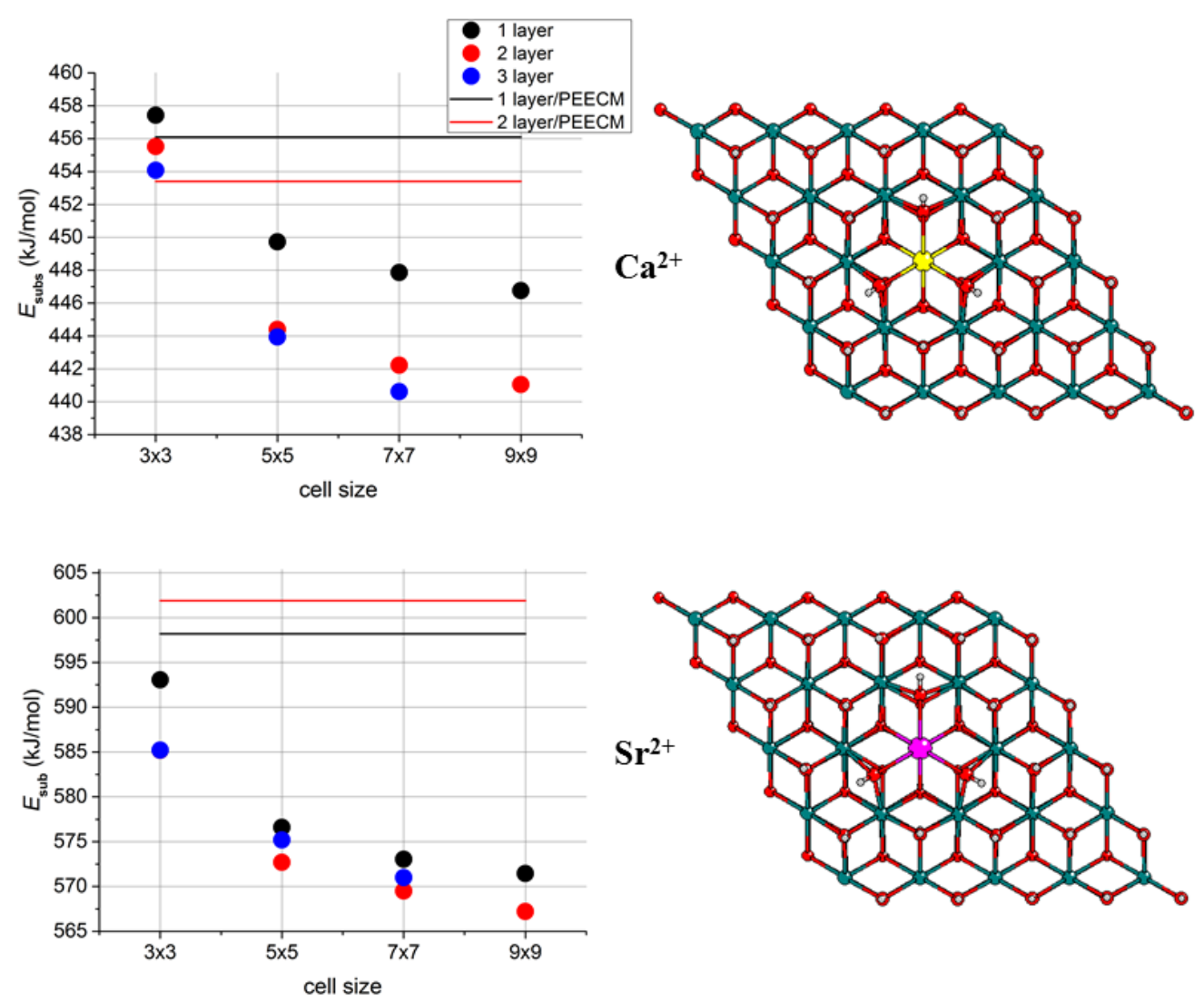

Figure 5: Periodic DFT-calculated substitution energies as a function of cell size for systems containing 1, 2 or 3 brucite layers for $\mathrm{Ca}^{2+}$ and $\mathrm{Sr}^{2+}$. Energies calculated for isolated systems in the PEECM method are represented with horizontal lines. Images are the optimised structures of substituted $\mathrm{Ca}^{2+}$ (yellow) and $\mathrm{Sr}^{2+}$ (magenta) into a $5 x 5 \_2$ brucite cell. $\left(\mathrm{Mg}=\right.$ green, $\mathrm{O}=$ red, $\mathrm{H}=$ grey). Note that the gradient of the $7 \times 7 \_3$ system did not fully converge (the max gradient was 0.000501 while the convergence criterion is 0.000450 ), although the energy did. 


\subsection{Adsorption of $\mathrm{Sr}\left[(\mathrm{OH})_{2}\left(\mathrm{H}_{2} \mathrm{O}\right)_{4}\right]$ on brucite}

Our ultimate aim is to understand the interactions between hydrated brucite surfaces and solvated, fission-generated strontium. This study will involve many differently coordinated complexes and will use their relative energies to identify the most stable among them. Here we describe a first step towards this aim, i.e. an investigation of adsorbed $\operatorname{Sr}(\mathrm{OH})_{2}$ complexes, surrounded by their first coordination shell. $\left[\mathrm{Sr}(\mathrm{OH})_{2}\left(\mathrm{H}_{2} \mathrm{O}\right)_{4}\right]$ was chosen based on the most stable $\mathrm{Sr}^{2+}$ dihydroxide coordination with two solvation shells from our previous study ${ }^{58}$. We searched for the most stable structure of $\left[\mathrm{Sr}(\mathrm{OH})_{2}\left(\mathrm{H}_{2} \mathrm{O}\right)_{4}\right]$ adsorbed on brucite by placing it above the surface, and by generating three more initial structures via random rotation of the original molecule. We optimised the geometries in CRYSTAL, representing the brucite surface by a single layer $5 \times 5$ supercell slab (Figure 6). These optimised geometries were then used as starting structures in our TURBOMOLE simulations, where they were reoptimised with the PEECM model, placing each complex at the same initial position relative to the $\mathrm{QM}$ cluster.

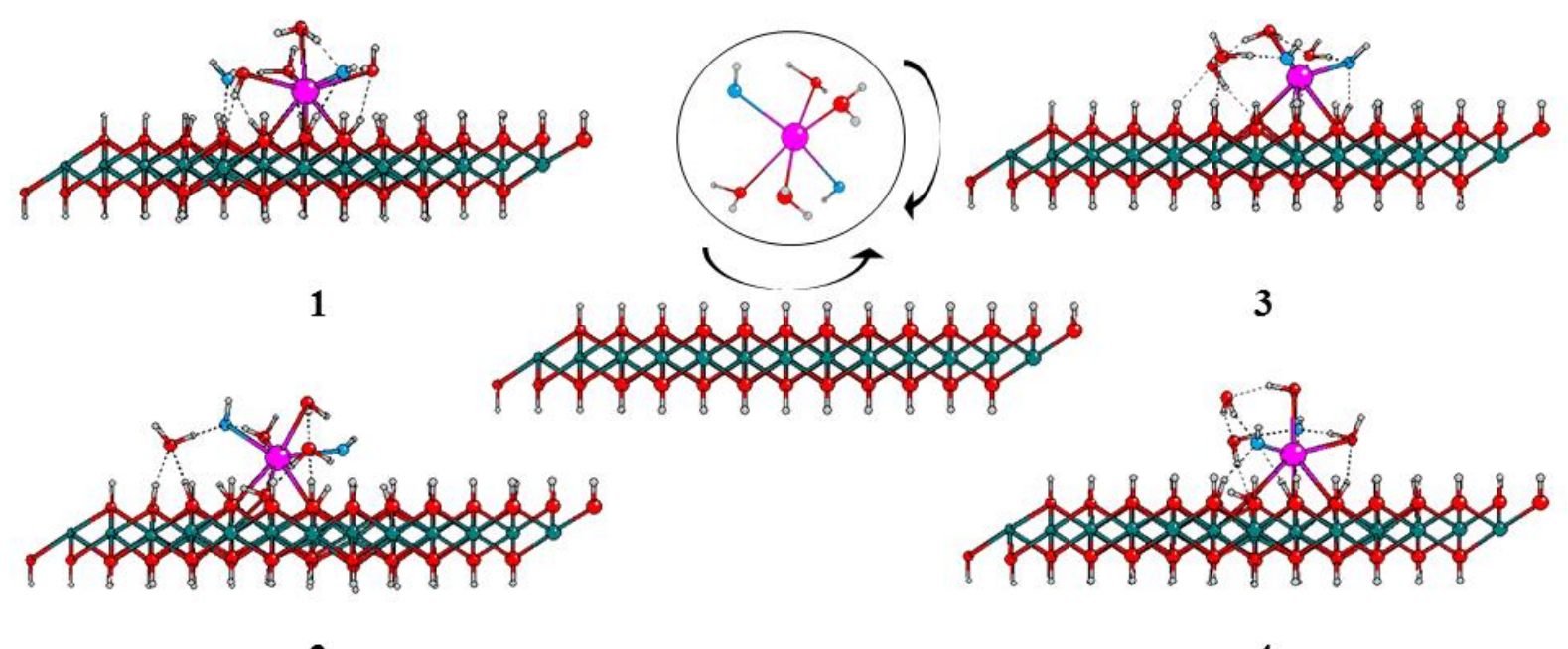

2

4

Figure 6: Middle: The ball and stick representation of the $5 x 5 \_1$ supercell and the original $\mathrm{Sr}(\mathrm{OH})_{2}$ complex with its complete $1^{\text {st }}$ coordination shell. Side: $1,2,3,4$ are the optimised structures of the adsorbed complexes with periodic DFT. (Mg=green, $\mathrm{O}=$ red, $\mathrm{H}=$ grey, $\mathrm{Sr}=$ magenta, $\mathrm{O}$ in the coordinated $\mathrm{OH}$ groups=blue)

We used an equation analogous to Eq. 1 in section 3.1 to calculate the adsorption energies (Table III), replacing the single point energy of a single ion with that of the solvated complex. There is excellent agreement between the absolute adsorption energies obtained from the two methods: the 
energy difference is between 1.6 and $3.6 \%$ in each case with a single layer surface representation and $0.2-4.0 \%$ for two-layered surface models. Structure 3 is predicted to be the most stable and the relative adsorption energies $\left(\Delta E_{\text {ads }}\right)$ are calculated by comparing the energies of the other structures to that of structure 3. The differences between the calculated relative energies are less than $2 \mathrm{~kJ} / \mathrm{mol}$ using periodic DFT ( $5 x 5$ cell size) and the PEECM model for the single layer surface representation, with the exception of structure 4, where the geometry of the optimised complexes differs between the two methods, therefore there is a more significant energy difference $(8 \mathrm{~kJ} / \mathrm{mol})$. Increasing the cell size up to $7 x 7$ and $9 x 9$ in periodic DFT causes a less than $5 \mathrm{~kJ} / \mathrm{mol}$ energy difference in the absolute adsorption energies. Although the values of the relative adsorption energy change more with bigger cell sizes compared with the excellent agreement showed for the $5 x 5$ and $6 x 6$ comparison, the energetic trend is not affected (the cell size study is shown in SM section 4). This suggests that the $5 x 5$ cell size is reasonable for periodic DFT and indirectly shows that the $6 x 6$ cluster size used in the PEECM contains all the atoms in the QM region which play a part in the adsorption.

BSSE was considered and the counterpoise corrected values are presented in brackets in Table III. BSSE significantly decreases the absolute adsorption energies (by c. $55-60 \mathrm{~kJ} / \mathrm{mol}$ ), but the relative energies are only slightly different from the uncorrected ones; this type of error largely cancels in the definition of the relative adsorption energy. ${ }^{88}$

When we consider a two-layer model in the PEECM, via either an extra PC layer $\left(\boldsymbol{6} \boldsymbol{x} 6 \_\mathbf{1}+\boldsymbol{P C}\right)$ or a second $6 \times 6$ cluster under the first $\left(6 x 6 \_2\right)$, the relative adsorption energies are found to be very similar to the single layer results $\left(6 x \boldsymbol{6} \_1\right)$. Comparing $\Delta E_{\text {ads }}$ for $6 x \boldsymbol{6} \_2$ and $5 x 5 \_2$ surface models, there are differences in relative adsorption energies in $5 x 5 \_2$ compared to $5 x 5 \_1$ due to minor structural differences affecting only water molecules which are not directly coordinated to the $\mathrm{Sr}^{2+}$ ion, but there is no change in terms of either energetic trends or coordination numbers.

Freezing layers beneath the surface in a slab structure is a common approach to mimic the behaviour of the bulk underneath the top layer(s). ${ }^{28}$ Although the biggest systems considered in this study contain only two-layered slabs, we calculated adsorption energies for surface representations in which the atomic positions in the second brucite layer are fixed $\left(6 x 6 \_2 \_f\right.$ and $\left.5 x 5 \_2 f\right)$ to study their possible effects on the adsorption. Turning to the periodic DFT results first, the adsorption energies for $5 x 5 \_2 \_$are within $\pm 2 \mathrm{~kJ} / \mathrm{mol}$ of to the $5 x 5 \_2$ results, i.e. fixing the atomic positions has no 
significant effect on the structures. In the case of the $6 x \boldsymbol{6} \_2 \_f$ PEECM model, $E_{\text {ads }}$ is $\sim 12 \mathrm{~kJ} / \mathrm{mol}$ higher than the adsorption energies of $6 x \boldsymbol{6} \_2$. Since comparing the optimised geometries did not reveal changes in the adsorbed structures, we surmise that this constant energy shift is probably due to the fact that, in addition to using constraints within the QM cluster, we used the experimental crystal parameters for the PEECM surface, while the crystal parameters were previously optimised for the bulk mineral structure in periodic DFT. But despite the less accurate crystal structure description in the embedded methods, $\Delta E_{\text {ads }}$ values are not affected by changes in the second layer, as shown in Table III: energies for $6 x \boldsymbol{6} \_2 \_f$ are very close to the $6 x \boldsymbol{6} \_\mathbf{1}$ and $6 \boldsymbol{x} \boldsymbol{6} \_\mathbf{2}$ results.

Overall, this study suggests that including a relaxed or fixed $2^{\text {nd }}$ layer in the surface model has only minor effects on the relatively weak adsorptions of the hydrated complexes. While there are some small differences in relative adsorption energies, the energetic trends within structures 1-4 and the geometries of the coordinated $\mathrm{Sr}^{2+}$ complexes do not change. Results obtained from periodic DFT and PEECM predict similar structures and have the same energetic trends. 


\begin{tabular}{|c|c|c|c|c|c|c|c|c|c|c|c|c|}
\hline \multicolumn{13}{|c|}{$E_{\text {ads }}(\mathbf{k J} / \mathbf{m o l})$} \\
\hline structure & \multicolumn{3}{|c|}{1} & \multicolumn{3}{|c|}{2} & \multicolumn{3}{|c|}{3} & \multicolumn{3}{|c|}{4} \\
\hline coordination & \multicolumn{3}{|c|}{$\mathrm{CN}=8$} & \multicolumn{3}{|c|}{$\mathrm{CN}=7-8$} & \multicolumn{3}{|c|}{$\mathrm{CN}=6$} & \multicolumn{3}{|c|}{$\mathrm{CN}=6-7$} \\
\hline Method & $\boldsymbol{E}$ & (BSSE) & $E_{\text {diff }}(\%)$ & $\boldsymbol{E}$ & (BSSE) & $E_{\text {diff }}(\%)$ & $\boldsymbol{E}$ & (BSSE) & $E_{\text {diff }}(\%)$ & $\boldsymbol{E}$ & (BSSE) & $E_{\text {diff }}(\%)$ \\
\hline Periodic DFT $5 x 5 \_1$ & -431.7 & & & -402.3 & & & -444.4 & & & -416.1 & & \\
\hline PEECM & -422.7 & $(-366.7)$ & 2.1 & -393.8 & $(-332.7)$ & 2.1 & -437.2 & $(-380.2)$ & 1.6 & -401.1 & $(-349.2)$ & 3.6 \\
\hline Periodic DFT $5 x 5 \_2$ & -428.4 & & & -403.2 & & & -438.6 & & & -419.9 & & \\
\hline PEECM & -424.6 & $(-371.2)$ & 0.9 & -391.8 & $(-332.4)$ & 2.8 & -439.6 & $(-384.3)$ & 0.2 & -403.3 & $(-353.0)$ & 4.0 \\
\hline Periodic DFT $5 x 5 \_2 \_f$ & -430.1 & & & -401.1 & & & -435.9 & & & -422.5 & & \\
\hline PEECM & -411.3 & $(-358.2)$ & 4.4 & -379.9 & $(-320.8)$ & 5.3 & -428.0 & $(-372.9)$ & 1.8 & -391.4 & $(-341.1)$ & 7.4 \\
\hline \multicolumn{13}{|c|}{$\Delta E_{\mathrm{ads}}(\mathrm{kJ} / \mathbf{m o l})$} \\
\hline Method & $\boldsymbol{E}$ & (BSSE) & & $\boldsymbol{E}$ & (BSSE) & & $\boldsymbol{E}$ & (BSSE) & & E ( & BSSE) & \\
\hline Periodic DFT $5 x 5 \_1$ & 12.7 & & & 42.1 & & & 0.0 & & & 28.2 & & \\
\hline PEECM $6 x 6 \_1$ & 14.5 & $(13.5)$ & & 43.4 & $(47.5)$ & & 0.0 & $(0.0)$ & & 36.1 & $(30.9)$ & \\
\hline Periodic DFT $5 x 5 \_2$ & 10.2 & & & 35.4 & & & 0.0 & & & 18.7 & & \\
\hline PEECM $\quad+P C$ & 14.2 & $(12.5)$ & & 49.0 & $(52.8)$ & & 0.0 & $(0.0)$ & & 34.0 & $(29.2)$ & \\
\hline РЕECM & 14.9 & (13.2) & & 47.8 & (51.9) & & 0.0 & $(0.0)$ & & 36.2 & (31.3) & \\
\hline PEECM & 16.7 & (14.7) & & 48.1 & (52.1) & & 0.0 & $(0.0)$ & & 36.6 & (31.8) & \\
\hline
\end{tabular}

TABLE III: Absolute $\left(E_{\text {ads }}\right)$ and relative adsorption energies $\left(\Delta E_{\text {ads }}\right)$ of four $\operatorname{Sr}\left[(\mathrm{OH})_{2}\left(\mathrm{H}_{2} \mathrm{O}\right)_{4}\right]$ complexes, calculated by comparing each system to the most stable structure. Counterpoise corrected energy values are presented in brackets (BSSE). 


\subsubsection{Assessment of local coordination via the QTAIM}

In order to probe further the comparison between the periodic DFT- and the PEECM-generated structures, we explored the coordination environment around the $\mathrm{Sr}^{2+}$ ion by examining the $\mathrm{Sr}-\mathrm{O}$ distances and by calculating QTAIM bond critical point (BCP) electron densities for the $\mathrm{Sr}-\mathrm{O}$ interactions (Table IV). The QTAIM is a well-known theory which uses the topology of the electron density to analyse atomic properties in molecules or complexes. ${ }^{89,90}$ Bond critical points are stationary points in the electron density distribution where the minimum along the path of maximum electron density between two nuclei is found at the interatomic surface. The electron density at the BCPs is often related to the strength of the interaction, ${ }^{91,92}$ with higher values indicating stronger bonds.

The final structures obtained with the two different methods are found to be generally very similar by topological analysis. The coordination environment of the $\mathrm{Sr}$ is almost the same in complexes $\mathbf{1}$ and $\mathbf{3}$, although there is a slight difference in structure 2, in which the $\mathrm{H}_{2} \mathrm{O}(3)$ water molecule (see structure 2 in Figure 7) is predicted to be very weakly coordinated to the $\mathrm{Sr}$ in the $\operatorname{PEECM}(\rho=0.0153$ a.u.), while there is no similar interaction between the $\mathrm{Sr}$ and that water molecule in the periodic DFT model. Defining coordination to be the presence of a $\mathrm{Sr}-\mathrm{O} \mathrm{BCP}$, we conclude that the overall coordination number $(\mathrm{CN})$ in complex 2 is 8 with PEECM and 7 with periodic DFT. The difference in the geometry of structure $\mathbf{4}$ is more significant (Figure 7); due to the different orientation of the $\mathrm{H}_{2} \mathrm{O}(3)$ water molecule in the embedded model, it is weakly coordinated to the $\mathrm{Sr}(d=2.941 \AA$, $\rho=0.0137$ a.u.) and it also modifies the strength of the other coordinated ligands, e.g. $\mathrm{OH}(5)$ has a shorter $\mathrm{Sr}-\mathrm{O}$ distance $(2.865 \AA)$ and higher electron density at the $\mathrm{BCP}(0.0133$ a.u. $)$ in the PEECM geometry than in the final structure of periodic DFT (3.072 $\mathrm{\AA}, 0.0083$ a.u.). 
TABLE IV: $\mathrm{Sr}$ - $\mathrm{O}$ distances $(d)$ and electron densities at the bond critical points $(\rho)$ for each coordinated $\mathrm{OH}$ group or $\mathrm{H}_{2} \mathrm{O}$ molecule calculated with QTAIM for the optimised structures in PEECM or periodic DFT. For structures and Sr-O labels see Figure 7. ${ }^{\text {an }}$ structure 1, there is a fourth water coordinated to the $\mathrm{Sr}$ instead of a fifth $\mathrm{OH}$ group.

\begin{tabular}{|c|c|c|c|c|c|c|c|c|c|c|c|c|c|c|c|c|}
\hline \multirow[b]{3}{*}{$\mathrm{Sr}-\mathrm{O}$} & \multicolumn{4}{|c|}{1} & \multicolumn{4}{|c|}{2} & \multicolumn{4}{|c|}{3} & \multicolumn{4}{|c|}{4} \\
\hline & \multicolumn{2}{|c|}{ PEECM } & \multicolumn{2}{|c|}{ Periodic DFT } & \multicolumn{2}{|c|}{ PEECM } & \multicolumn{2}{|c|}{ Periodic DFT } & \multicolumn{2}{|c|}{ PEECM } & \multicolumn{2}{|c|}{ Periodic DFT } & \multicolumn{2}{|c|}{ PEECM } & \multicolumn{2}{|c|}{ Periodic DFT } \\
\hline & $d(\AA)$ & $\begin{array}{c}\rho \\
\text { (a.u.) }\end{array}$ & $d(\AA)$ & $\begin{array}{c}\rho \\
\text { (a.u.) }\end{array}$ & $d(\AA)$ & $\begin{array}{c}\rho \\
\text { (a.u.) }\end{array}$ & $d(\AA)$ & $\begin{array}{c}\rho \\
(\text { a.u. })\end{array}$ & $d(\AA)$ & $\begin{array}{c}\rho \\
\text { (a.u.) } \\
\end{array}$ & $d(\AA)$ & $\begin{array}{c}\rho \\
(\text { a.u. })\end{array}$ & $d(\AA)$ & $\begin{array}{c}\rho \\
(\text { a.u. })\end{array}$ & $d(\AA)$ & $\begin{array}{c}\rho \\
\text { (a.u.) }\end{array}$ \\
\hline $\mathrm{Sr}-\mathrm{OH}(\mathbf{1})$ & 2.710 & 0.0230 & 2.698 & 0.0234 & 2.630 & 0.0276 & 2.612 & 0.0285 & 2.680 & 0.0247 & 2.700 & 0.0236 & 2.685 & 0.0243 & 2.751 & 0.0210 \\
\hline $\mathrm{Sr}-\mathrm{OH}(2)$ & 2.572 & 0.0314 & 2.566 & 0.0318 & 2.562 & 0.0315 & 2.582 & 0.0306 & 2.629 & 0.0275 & 2.623 & 0.0277 & 2.602 & 0.0296 & 2.579 & 0.0310 \\
\hline $\mathrm{Sr}-\mathrm{OH}(3)$ & 2.564 & 0.0322 & 2.555 & 0.0327 & 2.760 & 0.0213 & 2.672 & 0.0252 & 2.595 & 0.0299 & 2.577 & 0.0309 & 2.567 & 0.0315 & 2.519 & 0.0355 \\
\hline $\mathrm{Sr}-\mathrm{OH}(4)$ & 2.553 & 0.0278 & 2.597 & 0.0253 & 2.481 & 0.0378 & 2.512 & 0.0365 & 2.422 & 0.0407 & 2.438 & 0.0399 & 2.427 & 0.0406 & 2.422 & 0.0419 \\
\hline $\mathrm{Sr}-\mathrm{OH}(5)^{\mathrm{a}}$ & 2.724 & 0.0217 & 2.783 & 0.0192 & 2.574 & 0.0294 & 2.579 & 0.0304 & 2.470 & 0.0375 & 2.495 & 0.0361 & 2.865 & 0.0133 & 3.072 & 0.0083 \\
\hline $\mathrm{Sr}-\mathrm{H}_{2} \mathbf{O}(\mathbf{1})$ & 2.562 & 0.0311 & 2.583 & 0.0297 & 2.648 & 0.0274 & 2.642 & 0.0278 & 2.548 & 0.0336 & 2.574 & 0.0317 & 2.761 & 0.0205 & 2.853 & 0.0170 \\
\hline $\mathrm{Sr}-\mathrm{H}_{2} \mathrm{O}(2)$ & 2.624 & 0.0284 & 2.644 & 0.0270 & 2.746 & 0.0202 & 2.793 & 0.0181 & - & - & - & - & 2.644 & 0.0278 & 2.595 & 0.0309 \\
\hline $\mathrm{Sr}-\mathrm{H}_{2} \mathrm{O}(3)$ & 2.672 & 0.0255 & 2.695 & 0.0244 & 2.871 & 0.0153 & 3.331 & . & - & - & - & - & 2.941 & 0.0137 & 3.166 & - \\
\hline$R^{2}$ & \multicolumn{2}{|c|}{0.818} & \multicolumn{2}{|c|}{0.853} & \multicolumn{2}{|c|}{0.973} & \multicolumn{2}{|c|}{0.982} & \multicolumn{2}{|c|}{0.995} & \multicolumn{2}{|c|}{0.996} & \multicolumn{2}{|c|}{0.974} & \multicolumn{2}{|c|}{0.981} \\
\hline complex & \multicolumn{4}{|c|}{$\left[\mathrm{Sr}(\mathrm{OH})_{4}\left(\mathrm{H}_{2} \mathrm{O}\right)_{4}\right]^{2+}$} & \multicolumn{2}{|c|}{$\left[\mathrm{Sr}(\mathrm{OH})_{5}\left(\mathrm{H}_{2} \mathrm{O}\right)_{3}\right]^{3+}$} & \multicolumn{2}{|c|}{$\left[\mathrm{Sr}(\mathrm{OH})_{5}\left(\mathrm{H}_{2} \mathrm{O}\right)_{2}\right]^{3+}$} & \multicolumn{4}{|c|}{$\left[\mathrm{Sr}(\mathrm{OH})_{5}\left(\mathrm{H}_{2} \mathrm{O}\right)\right]^{3+}$} & \multicolumn{2}{|c|}{$\frac{\left[\mathrm{Sr}(\mathrm{OH})_{4}\left(\mathrm{H}_{2} \mathrm{O}\right)_{3}\right]^{2+}}{8}$} & \multicolumn{2}{|c|}{$\left[\mathrm{Sr}(\mathrm{OH})_{4}\left(\mathrm{H}_{2} \mathrm{O}\right)_{2}\right]^{2+}$} \\
\hline CN & \multicolumn{4}{|c|}{8} & \multicolumn{2}{|c|}{8} & \multicolumn{2}{|c|}{7} & \multicolumn{4}{|c|}{6} & \multicolumn{2}{|c|}{8} & \multicolumn{2}{|c|}{7} \\
\hline
\end{tabular}



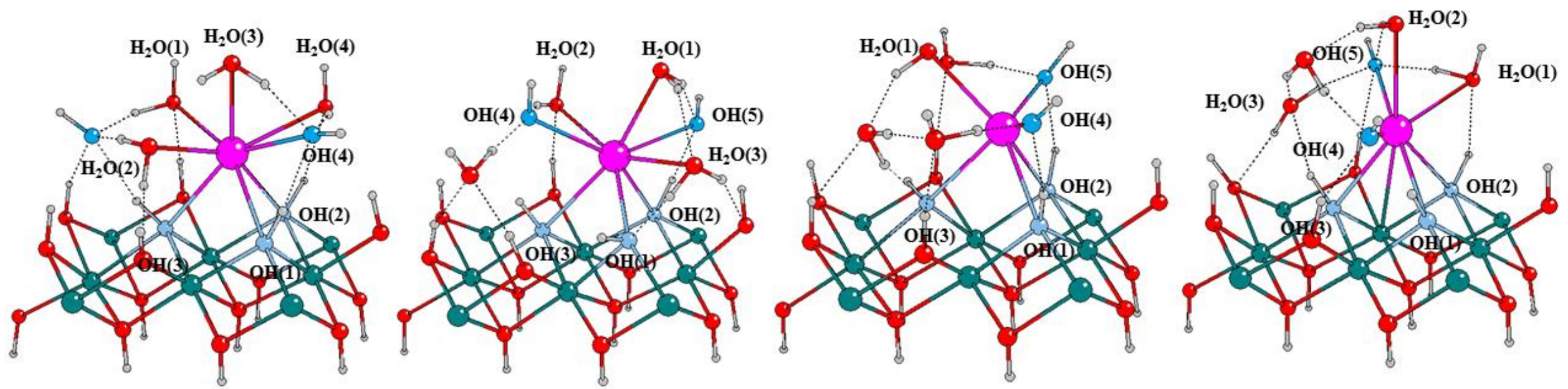

\section{PEECM}

\begin{tabular}{llll}
\hline 1 & 2 & 3 & 4 \\
\hline
\end{tabular}
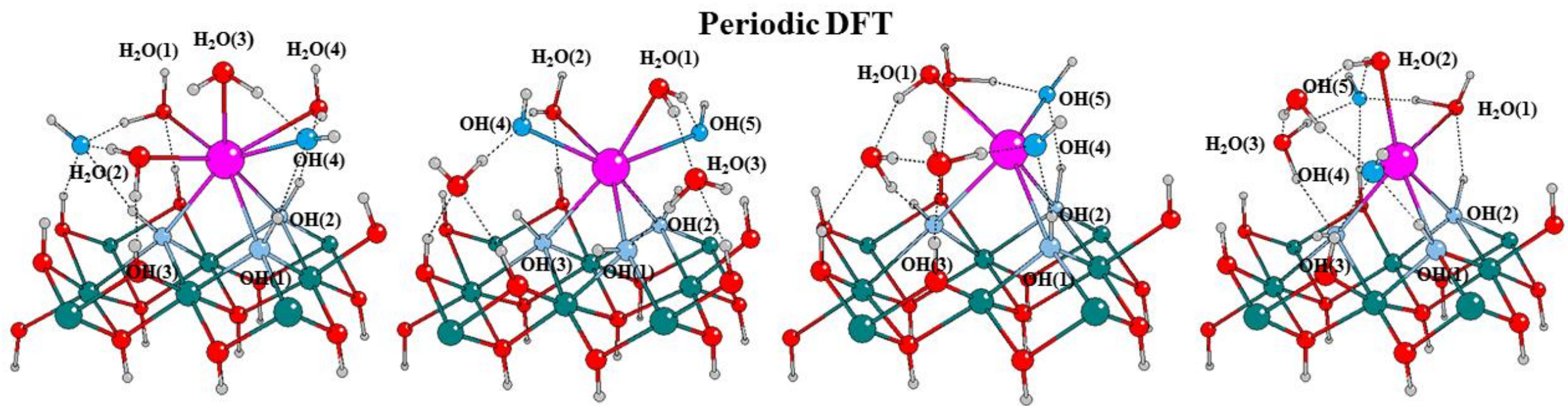

Figure 7: The optimised geometries of structures 1-4 in PEECM or periodic DFT. The coordinated $\mathrm{H}_{2} \mathrm{O}$ molecules and OH groups are labelled according to Table IV. (Mg=green, $\mathrm{O}=$ red, $\mathrm{H}=$ grey, $\mathrm{Sr}=$ magenta, $\mathrm{O}$ in the coordinated $\mathrm{OH}$ ion=dark blue, $\mathrm{O}$ in the coordinated $\mathrm{OH}$ groups of the surface=light blue) 
Previous studies predict a generally good correlation between BCP electron densities and related bond lengths $\mathrm{s}^{92-94}$ and indeed, plotting the electron densities at the BCPs against the $\mathrm{Sr}-\mathrm{O}$ distances (Figure 8) reveals a strong correlation between the two properties (calculated $R^{2}$ values for the linear regression are summarised in Table IV) and also illustrate the similarity in coordination between analogous structures calculated with PEECM and periodic DFT. There are three types of $\mathrm{Sr}-\mathrm{O}$ interactions, based on the type of the coordinating oxygen atom: $\mathrm{O}$ of the $\mathrm{OH}^{-}$ions in the solvation shell, surface $\mathrm{OH}$ groups (referred as $\mathrm{O}(\mathrm{OH})$ and $\mathrm{O}$ (surface) in the following text) and $\mathrm{H}_{2} \mathrm{O}$ molecules in the solvation shell $\left(\mathrm{O}\left(\mathrm{H}_{2} \mathrm{O}\right)\right)$. The ones expected to have the strongest interaction with the $\mathrm{Sr}^{2+}$ ion are the $\mathrm{OH}^{-}$ions in the solvation shell. However, this is not always the case, in fact, in structure $\mathbf{1}$ the only $\mathrm{OH}^{-}$ion directly coordinating to the $\mathrm{Sr}$ is slightly outstanding from the trend, resulting in an $R^{2}$ value of $0.818(0.853)$ with PEECM (periodic DFT). The $\mathrm{O}(\mathrm{OH})$ in this case has a weaker interaction according to the QTAIM analysis than the $\mathrm{Sr}-\mathrm{O}$ distance would suggest, but the reason for this behaviour is unknown. Furthermore, in structure 4, there is a very weakly coordinated $\mathrm{O}(\mathrm{OH})$ in the complex $(\mathrm{OH}(5))$, as opposed to the other $\mathrm{OH}$ ion, $\mathrm{OH}(4)$, which has the strongest coordination to the Sr ion. In structure $\mathbf{3}$, which is predicted to be the most stable, the $\mathrm{OH}^{-}$ions in the solvation shell have the strongest interaction, followed by the only coordinated water molecule and then the surface $\mathrm{OH}$ groups which exhibit the weakest interaction. 
PEECM
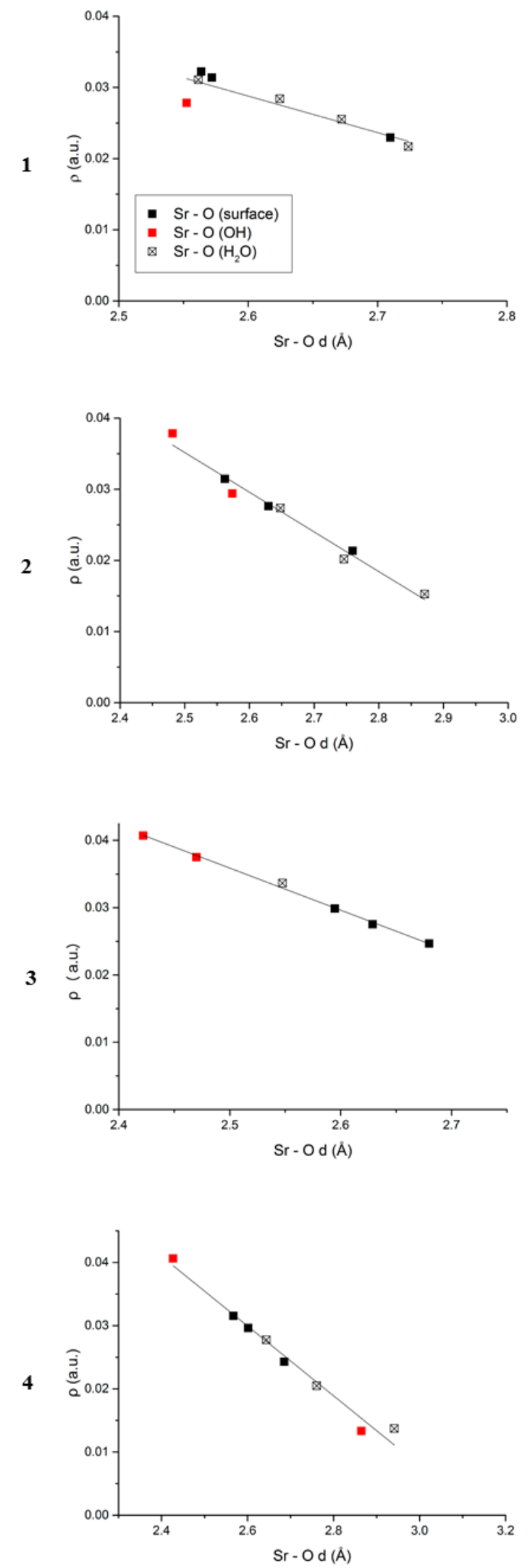

Periodic DFT
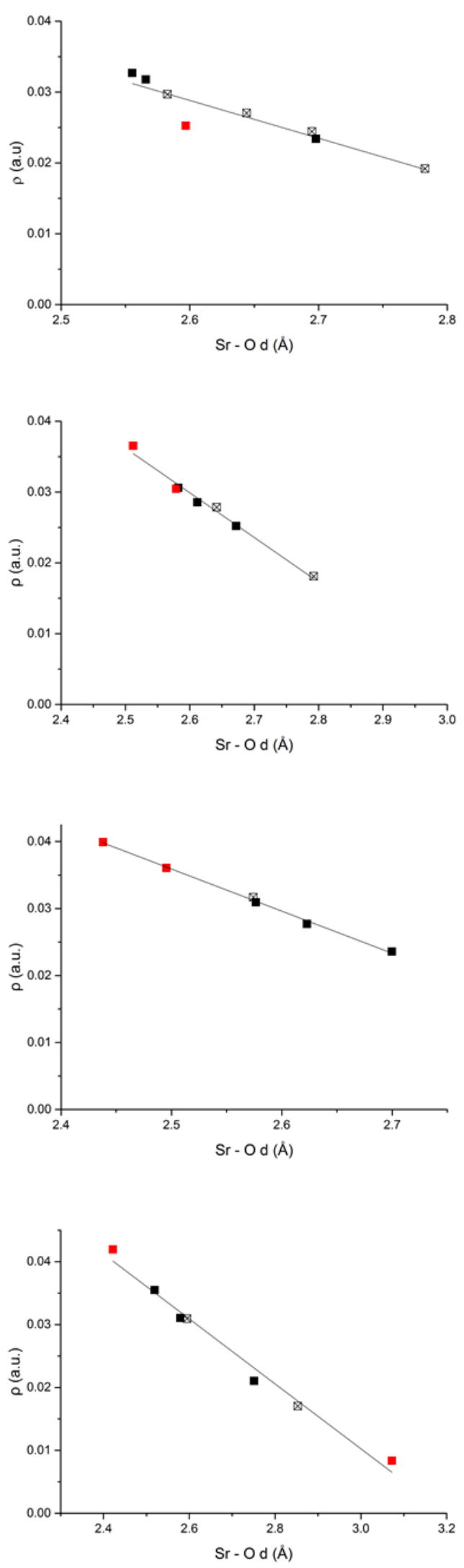

Figure 8: Electron densities at the $\mathrm{Sr}-\mathrm{O} \mathrm{BCPs}$ plotted against $\mathrm{Sr}-\mathrm{O}$ distances for the four $\mathrm{Sr}\left[(\mathrm{OH})_{2}\left(\mathrm{H}_{2} \mathrm{O}\right)_{4}\right]$ complexes optimised with PEECM or periodic DFT. Red squares are related to the $\mathrm{Sr}-\mathrm{O}(\mathrm{OH})$ interactions in the solvation shell, crossed squares to the $\mathrm{Sr}-\mathrm{O}\left(\mathrm{H}_{2} \mathrm{O}\right)$ interactions in the solvation shell and black squares to the $\mathrm{Sr}-\mathrm{O}$ (surface) interactions with the surface $\mathrm{OH}$ groups. 


\section{Conclusions}

The PEECM has been used for the first time to model a layered, not purely ionic surface (brucite (0001)) and the developed model has been tested in three studies related to our final goal, studying the adsorption of radioactive ions on hydrated brucite surfaces.

The PEECM is capable of describing the adsorption of single s block ions onto brucite, although the basis set quality has to be carefully considered. At least triple-zeta quality is necessary to obtain the correct energetic ordering between the ions, but these larger basis functions must be avoided in the QM representation of the surface cluster, since they can cause artificial interactions between the boundary atoms and the point charge region.

Through a comparison with periodic DFT, we have demonstrated that the PEECM sufficiently reflects the qualities of the brucite surface to be able to describe both the substitution of $\mathrm{Ca}^{2+}$ or $\mathrm{Sr}^{2+}$ into brucite and the surface complexation of $\left[\mathrm{Sr}(\mathrm{OH})_{2}\left(\mathrm{H}_{2} \mathrm{O}\right)_{4}\right]$. Based on the cell size studies and the interaction energies obtained with multiple layers of brucite, the size of the quantum chemically treated cluster is found to be reasonable in all cases. The agreement between adsorption energies and the optimised geometries obtained with PEECM or periodic DFT is excellent in the case of the adsorption of $\left[\mathrm{Sr}(\mathrm{OH})_{2}\left(\mathrm{H}_{2} \mathrm{O}\right)_{4}\right]$ complexes.

These results give us confidence in using the embedded brucite (0001) model in future investigations of $\mathrm{Sr}^{2+}$ and $\mathrm{Cs}^{+}$complex ion adsorptions on hydrated surfaces. They demonstrate that the PEECM is capable of describing sorption mechanisms on brucite-like surfaces, and that the approach is a viable alternative to periodic DFT when ionic species are involved in surface interactions. Furthermore, we note that the PEECM calculations presented here were run largely on our local departmental compute server, with a modest number of cores per calculation, by contrast to the periodic DFT calculations, which required the massively parallel version of the CRYSTAL code and were run on the UK's national supercomputing facility.

We are currently extending our PEECM study to include many more water molecules in the QM region to probe effects of second shell water molecules on the adsorption, and the results of this will be presented in a forthcoming paper. 


\section{Supplementary materials}

Supplementary material is available (where cited in the text) containing information such as the validation of the surface models with PEECM and periodic DFT, basis set comparison for the adsorption of $\mathrm{s}$ block ions and the cell size study for the $\operatorname{Sr}\left[(\mathrm{OH})_{2}\left(\mathrm{H}_{2} \mathrm{O}\right)_{4}\right]$ complexes with periodic DFT.

\section{Acknowledgments}

The authors are grateful to the Nuclear Decommissioning Authority and University College London for financial support for a PhD studentship to EM. AK thanks the EPSRC for the award of a career acceleration fellowship (grant EP/J002208/2). Via EM and NK's membership of the UK's HEC Materials Chemistry Consortium, which is funded by EPSRC (EP/L000202), this work used the ARCHER UK National Supercomputing Service (http://www.archer.ac.uk). In addition, the authors would like to acknowledge the use of the EPSRC's National Service for Computational Chemistry Software at Imperial College London, and are grateful for computing resources from UCL via the Research Computing "Legion” cluster (Legion@UCL) and associated services. 


\section{References}

${ }^{1}$ S. Chrétien and H. Metiu, J. Chem. Phys. 126, 104701 (2007).

${ }^{2}$ S.A. Fuente, C.A. Ferretti, N.F. Domancich, V.K. Díez, C.R. Apesteguía, J.I. Di Cosimo, R.M. Ferullo, and N.J. Castellani, Appl. Surf. Sci. 327, 268 (2015).

${ }^{3}$ S. Rangarajan and M. Mavrikakis, ACS Catal. 6, 2904 (2016).

${ }^{4}$ J.R.B. Gomes and J.A.N.F. Gomes, J. Electroanal. Chem. 483, 180 (2000).

${ }^{5}$ X.-Y. Pang, C. Wang, Y.-H. Zhou, J.-M. Zhao, and G.-C. Wang, J. Mol. Struct. THEOCHEM 948, 1 (2010).

${ }^{6}$ D. Costa, P.-A. Garrain, and M. Baaden, J. Biomed. Mater. Res. - Part A 101 A, 1210 (2013).

${ }^{7}$ S. Kerisit, P. Zarzycki, and K.M. Rosso, J. Phys. Chem. C 119, 9242 (2015).

${ }^{8}$ J. Setiadi, M.D. Arnold, and M.J. Ford, ACS Appl. Mater. Interfaces 5, 10690 (2013).

${ }^{9}$ H. Weber, T. Bredow, and B. Kirchner, J. Phys. Chem. C 119, 15137 (2015).

${ }^{10}$ M.P. Andersson, H. Sakuma, and S.L.S. Stipp, Langmuir 30, 6129 (2014).

${ }^{11}$ J.A. Greathouse, R.J. O’Brien, G. Bemis, and R.T. Pabalan, J. Phys. Chem. B 106, 1646 (2002).

${ }^{12}$ J.D. Kubicki, K.D. Kwon, K.W. Paul, and D.L. Sparks, Eur. J. Soil Sci. 58, 932 (2007).

${ }^{13}$ S. Lectez, J. Roques, M. Salanne, and E. Simoni, J. Chem. Phys. 137, 154705 (2012).

${ }^{14}$ E. Veilly, J. Roques, M.-C. Jodin-Caumon, B. Humbert, R. Drot, and E. Simoni, J. Chem. Phys. 129, 244704 (2008).

${ }^{15}$ S.E. Mason, C.R. Iceman, K.S. Tanwar, T.P. Trainor, and A.M. Chaka, J. Phys. Chem. C 113, 2159 (2009).

${ }^{16}$ S.E. Mason, T.P. Trainor, and A.M. Chaka, J. Phys. Chem. C 115, 4008 (2011).

${ }^{17}$ K.W. Corum and S.E. Mason, Mol. Simul. 41, 146 (2015).

${ }^{18}$ S. Yang, C. Chen, Y. Chen, J. Li, D. Wang, X. Wang, and W. Hu, Chempluschem 80, 480 (2015).

${ }^{19}$ S.K. Ramadugu and S.E. Mason, J. Phys. Chem. C 119, 18149 (2015).

${ }^{20}$ G. García, M. Atilhan, and S. Aparicio, Phys. Chem. Chem. Phys. 17, 16315 (2015).

${ }^{21}$ R. Dovesi, B. Civalleri, R. Orlando, C. Roetti, and V.R. Saunders, in Rev. Comput. Chem., edited by K.B. Lipkowitz, R. Larter, and T.R. Cundari (Wiley-VCH, 2005).

${ }^{22}$ G. Pacchioni, J. Chem. Phys. 128, 182505 (2008). 
${ }^{23}$ V. Ballenegger, A. Arnold, and J.J. Cerdà, J. Chem. Phys. 131, 094107 (2009).

${ }^{24}$ S.C. Ammal and A. Heyden, J. Chem. Phys. 133, 164703 (2010).

${ }^{25}$ J. Carrasco, N. Lopez, F. Illas, and H.J. Freund, J. Chem. Phys. 125, 074711 (2006).

${ }^{26}$ C.A. Gilbert, R. Smith, and S.D. Kenny, Nucl. Instruments Methods Phys. Res. Sect. B Beam Interact. with Mater. Atoms 255, 166 (2007).

${ }^{27}$ A.M. Burow, M. Sierka, J. Döbler, and J. Sauer, J. Chem. Phys. 130, 174710 (2009).

${ }^{28}$ A. V. Bandura, D.G. Sykes, V. Shapovalov, T.N. Troung, J.D. Kubicki, and R.A. Evarestov, J. Phys. Chem. B 108, 7844 (2004).

${ }^{29}$ B. Herschend, M. Baudin, and K. Hermansson, Chem. Phys. 328, 345 (2006).

${ }^{30}$ J.L.F. Da Silva, M.V. Ganduglia-Pirovano, J. Sauer, V. Bayer, and G. Kresse, Phys. Rev. B 75, 045121 (2007).

${ }^{31}$ in TURBOMOLE Version 6.5 USER's MANUAL, Progr. Packag. Ab Initio Electron. Struct. Calc. (2012), pp. 132-139.

${ }^{32}$ K.N. Kudin and G.E. Scuseria, Chem. Phys. Lett. 283, 61 (1998).

${ }^{33}$ Sellafield Ltd., Sellafield Integrated Waste Strategy Version 2 Report and Recommendations (2007).

${ }^{34}$ C.R. Gregson, D.T. Goddard, M.J. Sarsfield, and R.J. Taylor, J. Nucl. Mater. 412, 145 (2011).

${ }^{35}$ S. Owens, M. Higgins-Bos, M. Bankhead, and J. Austin, NNL Sci. 4 (2015).

${ }^{36}$ X. Tan, M. Fang, and X. Wang, Molecules 15, 8431 (2010).

${ }^{37}$ T. Hattori, T. Saito, K. Ishida, A.C. Scheinost, T. Tsuneda, S. Nagasaki, and S. Tanaka, Geochim. Cosmochim. Acta 73, 5975 (2009).

${ }^{38}$ A. Kremleva, S. Krüger, and N. Rösch, J. Phys. Chem. C 120, 324 (2016).

${ }^{39}$ F.M. Higgins, N.H. de Leeuw, and S.C. Parker, J. Mater. Chem. 12, 124 (2002).

${ }^{40}$ M. Johnson, D. O'Connor, P. Barnes, C.R.A. Catlow, S.L. Owens, G. Sankar, R. Bell, S.J. Teat, and R. Stephenson, J. Phys. Chem. B 107, 942 (2003).

${ }^{41}$ M. Catti, G. Ferraris, S. Hull, and A. Pavese, Phys. Chemsitry Miner. 22, 200 (1995).

${ }^{42}$ F. Zigan and R. Rothbauer, Neues Jahrb. Fuer Mineral. 4, 137 (1967).

${ }^{43}$ R. LeSar and R.G. Gordon, Phys. Rev. B 25, 7221 (1982).

${ }^{44}$ P. D’Arco, M. Causà, C. Roetti, and B. Silvi, Phys. Rev. B 47, 3522 (1993).

${ }^{45}$ B. Winkler, V. Milman, B. Hennion, M.C. Payne, M.-H. Lee, and J.S. Lin, Phys. Chemsitry Miner. 
22, $461(1995)$.

${ }^{46}$ P. Baranek, A. Lichanot, R. Orlando, and R. Dovesi, Chem. Phys. Lett. 340, 362 (2001).

${ }^{47}$ F. Pascale, S. Tosoni, C. Zicovich-Wilson, P. Ugliengo, R. Orlando, and R. Dovesi, Chem. Phys. Lett. 396, 308 (2004).

${ }^{48}$ P. Ugliengo, C.M. Zicovich-Wilson, S. Tosoni, and B. Civalleri, J. Mater. Chem. 19, 2564 (2009).

${ }^{49}$ K. Azuma, T. Oda, and S. Tanaka, Comput. Theor. Chem. 963, 215 (2011).

${ }^{50}$ A.M. Chaka and A.R. Felmy, J. Phys. Chem. A 118, 7469 (2014).

${ }^{51}$ M.B. Kruger, Q. Williams, and R. Jeanloz, J. Chem. Phys. 91, 5910 (1989).

${ }^{52}$ D.E. Haycock, M. Kasrai, C.J. Nicholls, and D.S. Urch, J. Chem. Soc. Dalt. Trans. 12, 1791 (1978).

${ }^{53}$ J.D. Bernal and H.D. Megaw, Proc. R. Soc. London A 151, 384 (1935).

${ }^{54}$ G. Wulff, Zeitschrift Fur Kryst. Und Mineral. 34, 449 (1901).

${ }^{55}$ M.R. Carrott, P. Carrott, M.B. de Carvalho, and K.S.W. Sing, J. Chem. Soc. Faraday Trans. 87, 185 (1991).

${ }^{56}$ A. Kerridge and N. Kaltsoyannis, Chem. a Eur. J. 17, 5060 (2011).

${ }^{57}$ A. Kerridge and N. Kaltsoyannis, Dalt. Trans. 40, 11258 (2011).

${ }^{58}$ E. Makkos, A. Kerridge, and N. Kaltsoyannis, Dalt. Trans. 44, 11572 (2015).

${ }^{59}$ E.H. Teunissen, A.P.J. Jansen, R.A. van Santen, R. Orlando, and R. Dovesi, J. Chem. Phys. 101, 5865 (1994).

${ }^{60}$ J.M. Vollmer, E. V Stefanovich, and T.N. Truong, J. Phys. Chem. B 103, 9415 (1999).

${ }^{61}$ TURBOMOLE V6.6 2014, a Development of University of Karlsruhe and Forschungszentrum Karlsruhe GmbH, 1989-2007, TURBOMOLE GmBH since 2007: Available from Http://www.turbomole.com.

${ }^{62}$ K. Eichkorn, O. Treutler, H. Öhm, M. Häser, and R. Ahlrichs, Chem. Phys. Lett. 242, 652 (1995).

${ }^{63}$ P. Ugliengo, G. Borzani, and D. Viterbo, J. Appl. Crystallogr. 21, 75 (1988).

${ }^{64}$ J. Tao, J.P. Perdew, V.N. Staroverov, and G.E. Scuseria, Phys. Rev. Lett. 91, 146401 (2003).

${ }^{65}$ A. Schäfer, H. Horn, and R. Ahlrichs, J. Chem. Phys. 97, 2571 (1992).

${ }^{66}$ K. Eichkorn, F. Weigend, O. Treutler, and R. Ahlrichs, Theor. Chem. Acc. 97, 119 (1997).

${ }^{67}$ For the $6 x \boldsymbol{6} \_\mathbf{1 + P C}$ surface representation, the lower hydrogen atoms were also constrained during optimisation. 
${ }^{68}$ J.P.W. Wellington, A. Kerridge, and N. Kaltsoyannis, Polyhedron 116, 57 (2016).

${ }^{69}$ A.E. Reed, R.B. Weinstock, and F. Weinhold, J. Chem. Phys. 83, 735 (1985).

${ }^{70}$ F. Weigend and R. Ahlrichs, Phys. Chem. Chem. Phys. 7, 3297 (2005).

${ }^{71}$ M. Kaupp, P. v R. Schleyer, H. Stoll, and H. Preuss, J. Chem. Phys. 94, 1360 (1991).

${ }^{72}$ W. Zou, D. Nori-Shargh, and J.E. Boggs, J. Phys. Chem. A 117, 207 (2013).

${ }^{73}$ T. Lu and F. Chen, J. Comput. Chem. 33, 580 (2012).

${ }^{74}$ This Image Was Made with VMD Software Support. VMD Is Developed with NIH Support Byt the Theoretical and Computational Biophysics Group at the Beckman Institute, University of Illinois at Urbana-Champaign. Http://www.ks.uiuc.edu/.

${ }^{75}$ T.A. Keith, AIMALL (Version 13.11.04), T. A. Keith, TK Gristmill Software, Overl. Park KS, USA, (aim.tkgristmill.com) (2013).

${ }^{76}$ R. Dovesi, V.R. Saunders, C. Roetti, R. Orlando, C.M. Zicovich-Wilson, F. Pascale, B. Civalleri, K. Doll, N.M. Harrison, I.J. Bush, P. D'Arco, M. Llunell, M. Causà, and Y. Noël, CRYSTAL14 User's Manual (University of Torino, Torino, 2014).

${ }^{77}$ R. Dovesi, R. Orlando, A. Erba, C.M. Zicovich-Wilson, B. Civalleri, S. Casassa, L. Maschio, M. Ferrabone, M. De La Pierre, P. D’Arco, Y. Noël, M. Causà, M. Rérat, and B. Kirtman, Int. J. Quantum Chem. 114, 1287 (2014).

${ }^{78}$ J.P. Perdew, K. Burke, and M. Ernzerhof, Phys. Rev. Lett. 77, 3865 (1996).

${ }^{79}$ S. Grimme, J. Antony, S. Ehrlich, and H. Krieg, J. Chem. Phys. 132, 154104 (2010).

${ }^{80}$ S. Grimme, J. Comput. Chem. 27, 1787 (2006).

${ }^{81}$ M.F. Peintinger, D.V. Oliveira, and T. Bredow, J. Comput. Chem. 34, 451 (2013).

${ }^{82}$ A. Erba, K.E. El-Kelany, M. Ferrero, I. Baraille, and M. Rérat, Phys. Rev. B 88, 035102 (2013).

${ }^{83}$ J.L.F. Da Silva, C. Stampfl, and M. Scheffler, Surf. Sci. 600, 703 (2006).

${ }^{84}$ Since we were using the same computational parameters, the calculated energies were essentially the same for isolated systems in vacuum with both CRYSTAL14 and TURBOMOLE with less than $10^{-6}$ a.u. difference.

${ }^{85}$ S.F. Boys and F. Bernardi, Mol. Phys. 19, 553 (1970).

${ }^{86}$ We explored further the effect of higher quality basis sets by using def2-QZVP for test calculations on single layered systems and found that the use of quadruple- $\zeta$ basis sets seemed to result in only a constant shift in adsorption energies when compared to triple- $\zeta$ results. (see SM Table (ix)). 
${ }^{87}$ Magnesium adsorption effectively incorporates an extra $\mathrm{Mg}$ ion into the $\mathrm{Mg}(\mathrm{OH})_{2}$ crystal structure; the ion-surface distance is much smaller in this case and the interaction much stronger, see SM Figure (i).

${ }^{88}$ We did not calculate the BSSE in CRYSTAL since it largely depends on the geometry and the basis functions employed, both of which are almost the same in the two methods. Hence we expect the BSSE to be very similar in the two models. Besides, the relative adsorption energies, in which we are primarily interested, are largely unaffected by this type of error.

${ }^{89}$ C.F. Matta and R.J. Boyd, An Introduction to the Quantum Theory of Atoms in Molecules (2007).

${ }^{90}$ R.F.W. Bader, Atoms in Molecules: A Quantum Theory (Oxford University Press, New York, 1990).

${ }^{91}$ A.R.E. Mountain and N. Kaltsoyannis, Dalt. Trans. 42, 13477 (2013).

${ }^{92}$ S.J. Grabowski, J. Phys. Org. Chem. 17, 18 (2004).

${ }^{93}$ B. Bankiewicz, P. Matczak, and M. Palusiak, J. Phys. Chem. A 116, 452 (2012).

${ }^{94}$ I. Alkorta, I. Rozas, and J. Elguero, Struct. Chem. 9, 243 (1998). 